\title{
DOS HOMENAJES A BEETHOVEN: LOS CUARTETOS DE PERE TINTORER (1814-1891) Y QUINTÍN ESQUEMBRE (1885-1965)
}

\author{
TWO HOMAGES TO BEETHOVEN: THE QUARTETS BY \\ PERE TINTORER (1814-1891) AND QUINTÍN ESQUEMBRE (1885-1965)
}

\author{
Christiane Heine \\ Universidad de Granada \\ cheine@ugr.es \\ ORCID ID: 0000-0003-2355-2142
}

\begin{abstract}
Resumen
El presente estudio constituye una aportación a la historia de la recepción de Ludwig van Beethoven en España durante la segunda mitad del siglo XIX y primer tercio del siglo XX, con especial atención a la creación musical, centrándose - dentro del marco del contexto histórico-musical del período- en dos composiciones camerísticas, una de Pere Tintorer (1814-1891) y otra de Quintín Esquembre (1885-1965). Ambos títulos se refieren explícitamente, en la portada de las respectivas partituras, al músico alemán, por lo cual se plantea la cuestión de cómo los dos españoles llevaron a cabo su aproximación al supuesto modelo y cuáles son los recursos compositivos empleados. El Cuarteto con piano en Do menor (ca. 1865) de Tintorer, titulado Un Souvenir de L. van Beethoven (en un movimiento, de forma durchkomponiert bipartita), toma un préstamo motívico procedente, probablemente, del Trío con piano en Do menor op. 1 n. 3 de Beethoven. Empleado a modo de motto, dicho motivo define la segunda parte de la obra al estar reiteradamente citado, en concreto, en la primera sección y en la coda, preñada esta última de un intenso trabajo motívico. En cambio, el Cuarteto de cuerda en Sol menor (1926) de Esquembre, designado Homenaje a Beethoven, renuncia a citas literales, optando en su lugar por la evocación deliberada de los tradicionales caracteres de sus cuatro movimientos. Estos están cíclicamente relacionados por medio de una "célula generadora" común, de la cual derivan concisos elementos rítmico-diastemáticos que, en parte, remiten a la tipología básica de diseños beethovenianos, actuando - de forma similar a estoscomo "motivos de desarrollo" (K. von Fischer, 1948; 2. a ed. 1972).
\end{abstract}

${ }^{1}$ El presente estudio surgió con ocasión del 250. aniversario del nacimiento de Ludwig van Beethoven (1770-1827). Mi especial agradecimiento para Teresa Cascudo García-Villaraco (Universidad de La Rioja) por motivar este trabajo y por realizar la revisión de la primera versión del texto.
(C) 2020 CSIC. Este es un artículo de acceso abierto distribuido bajo los términos de una licencia de uso y distribución Creative Commons Attribution 4.0 International (CC BY 4.0)

Cómo citar este artículo/Citation: Heine, Christiane. "Dos homenajes a Beethoven: los cuartetos de Pere Tintorer (1814-1891) y Quintín Esquembre (1885-1965)". Anuario Musical, 75 (2020), pp. 61-91. doi: https://doi.org/10.3989/anuariomusical.2020.75.04

\begin{abstract}
This study deals with the history of Ludwig van Beethoven's reception in Spain during the second half of the 19th century and the first third of the 20th century, with special attention to musical creation, focused - within the frame of the historical and musical context of the period - on two chamber compositions, one by Pere Tintorer (1814-1891) and another one by Quintín Esquembre (1885-1965). Both work titles on the cover of the respective scores refer explicitly to the German musician, and that is why the question arises: How did the two Spaniards carry out their approximation to the supposed model and what are the compositional resources employed? Tintorer's Piano Quartet in C minor (ca. 1865), entitled Un Souvenir de L. van Beethoven (in one movement, durchkomponiert in two parts), includes a motivic quotation, probably from Beethoven's Piano Trio in C minor op. 1 no. 3. Used as a kind of motto, this motif defines the second part of the work by being repeatedly cited, specifically in its first section and in the coda, the latter displaying an intensive motivic elaboration. In contrast, Esquembre's String Quartet in G minor (1926), named Homenaje a Beethoven, renounces to literal quotations, opting instead for the deliberate evocation of the traditional characters of its four movements. These are cyclically related by means of a common "generating cell" from which derive concise rhythmic-diastematic elements that, in part, refer to the basic typology of Beethoven's designs, acting - similarly to them - as "developmental motives" (K. von Fischer, 1948; $2^{\text {nd }}$ ed. 1972).
\end{abstract}




\section{Palabras clave}

Beethoven, Tintorer, Esquembre, música de cámara española, cuarteto de cuerda, cuarteto con piano, historia de la recepción, siglo XIX, siglo XX.

La historia de la recepción (Rezeptionsgeschichte) de Ludwig van Beethoven experimentó un primer impulso en la década de 1920 con cuatro estudios sobre su vida y obra realizados por Arnold Schmitz (1893-1980); ${ }^{2}$ su crítica acerca de la mitificación historiográfica de la figura del músico alemán quedó plasmada en el controvertido ensayo Das romantische Beethovenbild que se publicó en 1927 coincidiendo con el centenario del fallecimiento de Beethoven. ${ }^{3}$ A su vez, el bicentenario de su nacimiento (1970) fue motivo para que, cuatro décadas más tarde, Hans Heinrich Eggebrecht (1919-1999) revisara las fuentes escritas, analizando, en su monografía Zur Geschichte der Beethoven-Rezeption, aquellos materiales bibliográficos que aportan una "reflexión verbal sobre Beethoven [...] en relación con la interpretación del fenómeno Beethoven". ${ }^{4} \mathrm{Se}-$ gún relata Eggebrecht, una de las constantes al "hablar" sobre el compositor alemán es la presunción de "la unidad de vida y obra" de Beethoven, ${ }^{5}$ consecuencia del enfoque generalizado en aspectos más bien extramusicales -alentados, no obstante, por el propio músico mediante testimo-

${ }^{2}$ En su evaluación de las aportaciones musicológicas de Arnold Schmitz destaca Helmut Loos expresamente su mérito de haber iniciado la historia de la recepción de Beethoven; véase Helmut Loos, "Gegen den Strom der Zeit. Der Musikwissenschaftler Arnold Schmitz (1893-1980)", Musikgeschichte in Mittel- und Osteuropa. Mitteilungen der internationalen Arbeitsgemeinschaft an der Universität Leipzig, 13 (2012), pp. 232-244, especialmente 239; y, del mismo autor, "Arnold Schmitz as Beethoven Scholar: A Reassessment", Journal of Musicological Research, 32/2-3: New Beethoven Research (2013), pp. 150-162.

3 Arnold Schmitz, Das romantische Beethovenbild. Darstellung und Kritik (Berlin y Bonn: Dümmler, 1927; Darmstadt: Wissenschaftliche Buchgesellschaft, 1978).

${ }^{4}$ Hans Heinrich Eggebrecht, Zur Geschichte der Beethoven-Rezeption, Spektrum der Musik, 2, ed. Albrecht Riethmüller (Laaber: Laaber, 1972; nueva edición completada, 1994), pp. 7 y 13. Según lo explicado por el autor en el prefacio, Eggebrecht comenzó su ensayo en torno a 1968, en vísperas del bicentenario del nacimiento de Beethoven. En el presente estudio las traducciones del alemán son de la autora.

${ }^{5}$ Hans Heinrich Eggebrecht, Musik im Abendland. Prozesse und Stationen vom Mittelalter bis zur Gegenwart (Munich: Piper, 1991; edición de bolsillo revisada, 1996), p. 575.

\section{Keywords}

Beethoven, Tintorer, Esquembre, Spanish chamber music, string quartet, piano quartet, history of reception, 19th century, 20th century.

nios suyos verbalizados por escrito - que pueden resumirse en tres estados de ánimo: "sufrimiento", "voluntad" y "superación". 6 Convertidos en tópicos de la apreciación historiográfica, estas interpretaciones literarias aparecen comúnmente aplicadas a la producción musical beethoveniana, comprendida como "música de experiencias" (Erlebnismusik), concepto que además suele vincularse al supuesto "carácter ético" de sus obras.?

Harto de la persistencia de los enfoques meramente hermenéuticos que relacionan la música de Beethoven unilateralmente con "su famoso Weltschmerz, su 'tragedia' y todos los lugares comunes vertidos desde hace un siglo sobre este compositor", el joven Igor Stravinsky reclamó un cambio de aquella "actitud cerebral y sentimental que tiene tan poco que ver con un juicio musical serio" ya que, según estima, "es en la gran calidad de su sustancia sonora, y no en la naturaleza de sus ideas, donde reside su verdadera grandeza". ${ }^{8}$

Esta grandeza compositiva y constructiva de la obra de Beethoven, señalada por el músico ruso, ${ }^{9}$ naturalmente tampoco pasó desapercibida en España, donde su obra musical ha inspirado a generaciones de compositores, sirviéndoles de ejemplo especialmente en el ámbito de la música de cámara, poco estudiada al respecto hasta la fecha. ${ }^{10} \mathrm{El}$ hecho musical, tal como se manifiesta en la par-

${ }^{6}$ Algunos ejemplos de estos testimonios verbales de Beethoven pueden consultarse en Eggebrecht, Zur Geschichte der Beethoven-Rezeption, p. 40; véase también, del mismo autor, Musik im Abendland, pp. 574-575: 575.

${ }^{7}$ Eggebrecht, Musik im Abendland, p. 575.

8 Stravinsky hizo estas reflexiones con ocasión de la concepción de su sonata para piano (1924) al recuperar su interés en Beethoven tras años de distanciamiento a causa de la "deplorable pedagogía" sufrida durante los años de formación respecto a la veneración a Beethoven. Véase Igor Stravinsky, Crónicas de mi vida [1935/36], El Laberinto, 17, traducción [del francés], edición y notas de Jesús García-Pérez (Barcelona: Nuevo Arte Thor, 1985), pp. 125 y 127.

9 Stravinsky, Crónicas de mi vida, p. 127, destaca además en su visión retrospectiva sobre Beethoven "una fuerza de orden ante todo constructivo".

${ }^{10}$ Marie Winkelmüller, Die 'Drei Streichquartette' von Juan Crisóstomo de Arriaga. Ein Beitrag zur Beethoven-Rezep- 
titura, es precisamente el eje central del presente trabajo acerca de la recepción de Beethoven en España, investigada aquí desde el punto de vista de la historia de la composición (Kompositionsgeschichte), la cual representa una de las múltiples vías de aproximación a la recepción propuestas por Eggebrecht. ${ }^{11}$ El presente estudio está enfocado en analizar dos cuartetos - uno para piano e instrumentos de cuerdas, el otro solo para cuerdas - , compuestos por Pere Tintorer (1814-1891) en los años sesenta del siglo XIX y por Quintín Esquembre (1885-1965) en torno a 1926, con el fin de averiguar el impacto que el

tion in Paris um 1825, Freiburger Beiträge zur Musikgeschichte, 13 (Freiburg im Breisgau, Berlín y Viena: Rombach, 2009) ofrece una monografía pionera sobre la recepción de Beethoven en la obra musical de un compositor español. Véanse otras aportaciones, de menor envergadura, al estudio de la asimilación de rasgos estilístico-formales de Beethoven en selectos cuartetos de cuerda de origen español a cargo de: Diana Díaz González, 'El 'Cuarteto en Mi bemol en estilo antiguo' de Manuel Manrique de Lara", Revista de Musicología, 36/1-2 (2013), pp. 281-308; Christiane Heine, "Streichquartettkomposition in Spanien im 19. Jahrhundert: eine inexistente Gattung?", en The String Quartet: From the Private to the Public Sphere, Speculum Musicæ, 27, ed. Christian Speck (Turnhout: Brepols, 2016), pp. 333-369; y, de la misma autora, "Die zweite Blüte: Spanische Streichquartettproduktion im frühen 20. Jahrhundert", en The String Quartet in Spain, Varia Musicologica, 22, ed. Christiane Heine y Juan Miguel González Martínez (Berna: Peter Lang, 2016), pp. 121-299.

${ }^{11}$ Eggebrecht, Zur Geschichte der Beethoven-Rezeption, p. 13. Para más información sobre la recepción de Beethoven en otros países europeos, véanse, por ejemplo, Niels Krabbe, "The Reception of Beethoven in Copenhagen in the 19th Century”, Musik Forskning, 21 (1995), pp. 160-210; Beate Angelika Kraus, Beethoven-Rezeption in Frankreich: Von ihren Anfängen bis zum Untergang des Second Empire (Bonn: Verlag des Beethoven-Hauses, 1998); de la misma autora, "Europas Beethoven: Ein rezeptionsgeschichtlicher Vergleich", Bonner Beethoven-Studien, 3 (2003), pp. 47-79; Matthias Brzoska, "Beethoven der Gekreuzigte: Aspekte frenetischer Beethoven-Rezeption in Frankreich", Archiv für Musikwissenschaft, 71/2 (2014), pp. 85-98; Aaron S. Allen, "Beethoven as 'Pianista'? The Reception of Beethoven's Piano Music in Italy through the 1860s", Arietta. Journal of the Beethoven Piano Society of Europe, 8 (2014), pp. 48-60; y Helmut Loos y Klaus-Peter Koch, eds., Beethoven-Rezeption in Mittel- und Osteuropa, Bericht über die Internationale Musikwissenschaftliche Konferenz vom 22. bis 26. Oktober 2014 in Leipzig (Leipzig: Gudrun Schröder, 2015). fervor expreso de ambos autores por la figura de Beethoven pudiera haber tenido en sus correspondientes estilos compositivos. Los mencionados cuartetos son particularmente aptos para indagar - en el contexto histórico-musical del período explorado- las supuestas intenciones estéticas de sus autores por referirse, a través de los títulos, de manera inequívoca al músico conmemorado: Un Souvenir de L. van Beethoven en el caso de Tintorer y Homenaje a Beethoven en el caso de Esquembre. Dichas alusiones sugieren la hipótesis de que tanto Tintorer como Esquembre adoptaron deliberadamente algunos recursos y procedimientos de los modelos beethovenianos para llevar a cabo sus homenajes musicales. En las siguientes líneas, los respectivos tratamientos compositivos serán sometidos primero a un detallado examen y luego a la comparación, con el propósito de resaltar las semejanzas y diferencias entre ambos cuartetos, que suponen ejemplos representativos de la recepción de Beethoven en la música de cámara española.

\section{UN SOUVENIR DE L. VAN BEETHOVEN (ca. 1865) DE PERE TINTORER}

Dentro del repertorio instrumental de Beethoven, el género del cuarteto de cuerda, junto a la sonata para piano, es el que más ha repercutido en la producción europea de música de cámara, tanto entre compositores coetáneos como entre las generaciones siguientes. ${ }^{12}$ Un ejemplo temprano de un músico español orientado hacia Beethoven lo brinda - aún en vida de este - Juan Crisóstomo de Arriaga (1806-1826) a través de sus tres cuartetos de cuerda, compuestos y editados en París (ca. 1824), que son testimonios de una precoz maestría, apoyada formal y estilísticamente en su modelo merced a su estancia formativa en la capital francesa, como logró demostrar Marie Winkelmüller con su análisis pormenorizado de estas obras camerísticas. ${ }^{13}$ En cambio, dentro de España la asi-

12 Véanse a modo de ejemplo las numerosas referencias a Beethoven en dos publicaciones monográficas sobre el género del cuarteto de cuerda: Friedhelm Krummacher, Geschichte des Streichquartetts (= Das Streichquartett, Handbuch der musikalischen Gattungen, 6, ed. Siegfried Mauser), 2 vols. (Laaber: Laaber, 2001 y 2003; nueva edición, 3 vols., 2005); y Bernard Fournier (en colaboración con Roseline Kassap-Riefenstahl), Histoire du quatuor à cordes, 3 vols. (Paris: Fayard, 2010).

13 Winkelmüller, Die 'Drei Streichquartette' von Juan Crisóstomo de Arriaga. 
milación de la música de cámara de Beethoven no se llevó a cabo sino en la segunda mitad del siglo XIX, una vez concluida la transición de la práctica musical desde la esfera privada a la esfera pública. ${ }^{14}$ Un papel importante en la difusión de la música clásica vienesa fue desempeñado por la Sociedad de Cuartetos de Madrid (SCM), fundada en 1863 , entre cuyos propósitos, de hecho, no figuraba la promoción de la producción autóctona. ${ }^{15}$ Aclamado por la crítica de la época como "el músico por escelencia [sic] de los tiempos actuales", ${ }_{16}$ Beethoven estuvo presente en los conciertos de la SCM desde la primera sesión, que se inauguró con su Cuarteto de cuerda en Re mayor op. $18 \mathrm{n}$. $^{\circ} 3$ y la Sonata para violín y piano en $\mathrm{Fa}$ mayor op. 24. A lo largo de los ciento veintiún conciertos realizados hasta 1894 por la SCM, Beethoven fue el compositor más interpretado (con 206 audiciones) ${ }^{17}$ aunque cabe destacar que los madrileños pudieron escuchar, en algunos casos repetidas veces, casi exclusivamente solo las obras de los períodos temprano y medio..$^{18}$ Asimismo, la efímera Sociedad de Música Clásica di Camera en torno a José Tragó y Enrique Fernández Arbós privilegió a

14 Para más información sobre esta transición, véase Heine, "Streichquartettkomposition in Spanien im 19. Jahrhundert: eine inexistente Gattung?".

15 En los 121 conciertos ofrecidos hasta 1894 por la SCM durante los 31 años de su existencia se interpretaron tan solo diez obras diferentes de siete compositores españoles (entre ellos únicamente tres cuartetos de cuerda, dos de Juan Crisóstomo de Arriaga y uno de Rafael Pérez), y solamente en una ocasión fue ofrecido un programa monográfico con repertorio nacional. Para obtener información detallada sobre la SCM, véanse Mónica García Velasco, "La Sociedad de Cuartetos de Madrid (1863-1894)", Cuadernos de Música Iberoamericana, 8-9 (2001), pp. 149-193; y Ester Aguado Sánchez, "El repertorio interpretado por la Sociedad de Cuartetos de Madrid (18631894)", Música. Revista del Real Conservatorio Superior de Música de Madrid, 7-9 (2000-2002), pp. 27-140.

16 Vicente Cuenca, "Sociedad de Cuartetos", El Artista, 1/26 (30-XI-1866), pp. 4-5: 4; el mismo texto volvió a publicarse en El Artista, 3/35 (22-II-1868), pp. 181-184: 182.

17 Aguado Sánchez, "El repertorio interpretado", p. 103. El repertorio beethoveniano interpretado en los conciertos de la SCM incluyó también sonatas para piano solo además de obras camerísticas.

18 En cuanto al género del cuarteto de cuerda, la SCM interpretó de Beethoven los op. 18 n. ${ }^{\text {o } 1-6, ~ o p . ~} 56$ n. ${ }^{\text {o } 1-3, ~ o p . ~} 74$ y op. 132 (este último solo en 1890); véase Aguado Sánchez, "El repertorio interpretado", pp. 128-129.
Beethoven en doce conciertos ofrecidos entre 1889 y 1891 en el Salón Romero de Madrid, de los cuales dos sesiones estuvieron íntegramente dedicadas a su música de cámara. ${ }^{19}$

Tras décadas marcadas por el estancamiento de la producción camerística padecido después de Arriaga en la primera mitad del siglo XIX, especialmente del género del cuarteto de cuerda después de su primer florecimiento, era de esperar que el creciente interés por parte del público español en el repertorio del clasicismo vienés en general y de Beethoven en particular resultaría muy positivo. ${ }^{20}$ Ese interés - fomentado primero en Madrid por la SCM y luego también en otros lugares de España con la creación de nuevas sociedades musicales - estimularía la creación autóctona, según lo augurado en 1867 por el crítico de la Revista y Gaceta Musical en referencia a las actividades de la SCM: ${ }^{21}$

Prosigan, pues, por ese camino estos distinguidos profesores, que el público, que es justo apreciador de lo bueno, sabrá recompensar sus esfuerzos, y al mismo tiempo abrirán también así un nuevo campo a las justas y exactas apreciaciones que el público se irá acostumbrando a hacer de la buena música, lo que podrá influir mucho en el porvenir del arte en nuestra patria. ${ }^{22}$

Efectivamente, la paulatina recuperación creadora del cuarteto de cuerda emprendida en el último tercio del siglo XIX por unos pocos compositores españoles está estrechamente relacionada con la recepción de los modelos clásicos, sobre todo de las tempranas series de cuartetos de Joseph Haydn (los op. 9, 17 y 20, Hob. III:19-36) y Beethoven (op. 18), como quedó demostrado a través del análisis de obras de Tomás Bretón (1850-

\footnotetext{
19 María Almudena Sánchez, "La Sociedad de Música Clásica di Camera", Cuadernos de Música Iberoamericana, 8-9 (2001), pp. 195-210: 210.

20 Véanse con respecto al "primer florecimiento" del género del cuarteto de cuerda los estudios de Miguel Ángel Marín, Christian Speck, Walter Kurt Kreyszig, Màrius Bernadó / José María Domínguez y Jorge Fonseca, recogidos en Christiane Heine y Juan Miguel González Martínez, eds., The String Quartet in Spain, Varia Musicologica, 22 (Berna: Peter Lang, 2016).

${ }^{21}$ Aparte de la sociedad madrileña se constituyeron Sociedades de Cuartetos en Cádiz (1866), Valencia (1868), Valladolid (ca. 1870), Barcelona (1872) y Vitoria (1879).

22 J. V. R., "Sociedad de Cuartetos", Revista y Gaceta Musical, 1/51 (22-XII-1867), p. 275.
} 
1923), ${ }^{23}$ Salvador Giner (1832-1911) ${ }^{24}$ y Marcial del Adalid (1826-1881), ${ }^{25}$ sus obras comparten la tendencia hacia un lenguaje musical universal, exento de elementos populares y otros recursos identificatorios de su origen. Sin embargo, Bretón y Giner parecen haberse orientado mayormente en Haydn, a diferencia de Adalid, cuyos Cuartetos op. 58 y op. 16, ambos en Sol mayor, muestran algunas afinidades de índole formal y estilística con los Cuartetos op. 18 nos. 3, 5 y 6 de Beethoven, sobre todo en lo que concierne al planteamiento tonal, al tratamiento motívico y a la organización de las respectivas formas sonata. ${ }^{26}$

Frente a las muestras del nexo intrínseco con el clasicismo vienés, averiguado en estas obras mediante el análisis de los correspondientes procedimientos compositivos, la devoción por Beethoven queda explícitamente manifiesta en el único cuarteto conservado de Pere Tinto-

${ }^{23}$ Para consultar características estilístico-formales del Cuarteto en Sol mayor (1866) de Tomás Bretón, véase Heine, "Streichquartettkomposition in Spanien im 19. Jahrhundert", pp. 344-348.

${ }^{24}$ Un detallado análisis del Cuarteto en Sol mayor n. ${ }^{\circ} 2$ (1871?) de Salvador Giner puede consultarse en Heine, "Streichquartettkomposition in Spanien im 19. Jahrhundert", pp. 348357 ; véanse asimismo las respectivas introducciones a las ediciones críticas de los cuartetos nos. 1 y 2 de Giner en Christiane Heine, ed., Salvador Giner (1832-1911). String Quartet No. 1 in $G$ major / Cuarteto de cuerda N. 1 en Sol mayor, 19th Century Spanish String Quartets / Cuartetos de cuerda españoles del siglo XIX, ed. y dir. Christiane Heine (Madrid: Ediciones Eudora S. L., 2017), pp. 11-14; y, de la misma editora, String Quartet No. 2 in G major / Cuarteto de cuerda N. ${ }^{\circ} 2$ en Sol mayor, Ibidem, pp. 11-14.

${ }^{25}$ Un análisis comparativo de los Cuartetos en Sol mayor op. 58 (antes de 1867?) y op. 16 (1872) de Marcial del Adalid se encuentra en Heine, "Streichquartettkomposition in Spanien im 19. Jahrhundert”, pp. 357-363; véase además la introducción a la edición crítica del op. 58 en Christiane Heine, ed., Marcial del Adalid (1826-1881). String Quartet in G major op. 58 / Cuarteto de cuerda en Sol mayor op. 58, 19th Century Spanish String Quartets / Cuartetos de cuerda españoles del siglo XIX, ed. y dir. Christiane Heine (Madrid: Ediciones Eudora S. L., 2017), pp. 11-14.

${ }^{26}$ El Cuarteto en Sol mayor op. 16 (numeración según el cómputo nuevo) de Adalid constituye una refundición parcial del anterior Cuarteto op. 58 que afecta a tres de los cuatro movimientos. Para consultar detalles respecto a la génesis de ambos cuartetos, véase Heine, "Streichquartettkomposition in Spanien im 19. Jahrhundert”, pp. 358-359. rer, para piano y cuerdas, cuyo título - Un Souvenir de L. van Beethoven - alude de manera inequívoca a su ídolo alemán. ${ }^{27}$ Nacido en Palma de Mallorca en 1814, aunque con raíces catalanas por parte de sus padres, el pianista y compositor Pere [Pedro] Tintorer i Segarra pasó un largo período en Francia - desde 1834 en París, para completar su formación, y a partir de 1836 en Lyon, donde residiría durante catorce años dedicado a la enseñanza musicalantes de asentarse definitivamente en Barcelona en $1849 .{ }^{28}$ En España logró un gran prestigio como concertista y docente, si bien es verdad que el reconocimiento institucional no le llegó hasta décadas más tarde, en 1883, con su nombramiento de Profesor de piano en el Conservatorio del Liceo barcelonés. ${ }^{29}$ Dada su condición de pianista, no es de extrañar que la mayor parte de su producción compositiva pertenezca al repertorio de su instrumento. ${ }^{30}$ Sus incursiones ocasionales en el ámbito

27 Según el listado de Saldoni, Tintorer compuso (hasta 1868) un total de tres cuartetos para piano, violín, viola y violonchelo, así como un cuarteto de cuerda, de los cuales solo está localizado el cuarteto objeto del presente análisis ("publicado en París en casa de Richault"); véase Baltasar Saldoni, "Día 12, 1814", Diccionario biográfico-bibliográfico de efemérides de músicos españoles, 4 vols. (Madrid, Imprenta a cargo de D. Antonio Pérez Dubrull, 1868-1881), vol. 1, 1868, pp. 251-252: 252 .

28 Datos biográficos según Isabel Paulo Selvi, "Capítulo V/5.1 Pere Tintorer y Sagarra", en "La influencia de Liszt en el panorama musical hispano a raíz de su estancia en la Península Ibérica", tesis doctoral, Universidad de La Rioja, 2017, pp. 362386. En las fuentes bibliográficas existen discrepancias respecto a la ortografía del segundo apellido de Tintorer que varía entre Segarra y Sagarra, empleados en algún caso indiscriminadamente a la vez (es el caso de la mencionada tesis doctoral de Paulo Selvi), si bien parece que la primera versión, Segarra, es la más utilizada desde Saldoni, "Día 12, 1814”, p. 251.

${ }^{29}$ La dilatada experiencia como pianista y docente de Tintorer queda reflejada en la publicación de varios tomos de un Curso completo de piano. Método teórico-práctico, dividido en dos partes (Barcelona: Faustino Bernareggi, [1878]) y una curiosa Gimnasia diaria del pianista (Barcelona: Ferrer de Climent e Hijos, [1886]). El nombramiento de Tintorer como "profesor de piano del conservatorio musical de Barcelona" fue saludado por la prensa local; véase La Ilustración musical, 1/33 (17-XI1883 ), p. 4 (referencia bibliográfica indicada por Paulo Selvi, "La influencia de Liszt", p. 368).

${ }^{30}$ Muchas de las obras para piano de Tintorer son de índole didáctica. Un buen número de sus composiciones, editadas supuestamente en vida del compositor, está disponible en la Bi- 
de la música de cámara estuvieron ligadas a aquellos géneros que incluyen el piano, tal como es el caso de dos obras de mayor envergadura: el Trío para piano, violín y violonchelo en $\mathrm{Fa}$ mayor $^{31}$ y el Cuarteto para piano, violín, viola y violonchelo en Do menor, ambos editados en París en torno a $1865 ;{ }^{32}$ el cuarteto lo publicó la casa editorial S. Richault con la siguiente portada: ${ }^{33}$

Un
SOUVENIR de L. VAN BEETHOVEN
QUATUOR
pour
Piano, Violon, Alto et Basse
dédié à
M. F. Frontera de Valdemosa
PAR
Professeur de Chant de Reine Isabelle II
P. TINORER

blioteca Nacional de España en Madrid (E-Mn), parcialmente digitalizadas en Biblioteca Digital Hispánica (http://www.bne. es/es/Catalogos/BibliotecaDigitalHispanica/Inicio/index.html), $\mathrm{y}$ en la Biblioteca de Catalunya en Barcelona (E-Bc).

${ }^{31}$ Un ejemplar de la partitura manuscrita (sin fecha y sin firma) del Trío con piano en Fa mayor de Tintorer se encuentra en E-Mn, signatura M/GUELBENZU/1549, accesible a través de Biblioteca Digital Hispánica. El trío se estrenó en Barcelona el 29 de junio de 1865; la primera edición la publicó $\mathrm{E}$. Gérard et $\mathrm{C}^{\mathrm{ie}}$ [s. f.] en París. Su fecha de composición es incierta, pero puede situarse entre ca. 1856 y ca. 1863, según lo propuesto por Torcuato Tejada Tauste, "El Trío con piano en España en los siglos XIX y XX", tesis doctoral, Universidad de Granada, 2020, pp. 67-70; un minucioso análisis de dicha obra se encuentra en pp. 163-179.

${ }^{32}$ Fecha aproximada de la edición del cuarteto con piano según Tejada Tauste, "El Trío con piano", p. 178.

${ }^{33} \mathrm{El}$ autógrafo del cuarteto con piano no está localizado. La primera edición del cuarteto de Tintorer en la Biblioteca Nacional es accesible en línea en Biblioteca Digital Hispánica. Existe también una edición revisada: Pere Tintorer Quartet en Do menor per a violi, viola, violoncel i piano, ed. Jordi Domènech (Barcelona: Dinsic Publicacions Musicals, S. L., 2009). Aparte de estas dos ediciones se conoce una versión impresa (partitura y partichelas) realizada por Patrick Meadows titulada Quartetino per a violi, viola, violoncel i piano (Mallorca 1994, según Biblioteca de Catalunya; D. L. 2002, según Biblioteca Nacional de España), la cual no ha podido ser consultada para el presente estudio (E-Bc, signatura M-4-C 7/21; E-Mn, signaturas MP/L4247/11 y DLMP/4247/11). Ese diminutivo del título (Quartetino...) ha sido adoptado por el Trio Reger y la pianista Maria Victòria Cortés para su grabación en CD del cuarteto (Pere Tintorer / [1814-1891] / Música de cambra / Chamber music, Sabadell: La mà de guido, 2004 [LMG 2059]).
El "souvenir" de Beethoven, aludido en el título, parece referirse al préstamo musical que Tintorer realizó supuestamente en su cuarteto con piano, al servirse de un motto que podría tener su origen en el Trío con piano en Do menor op. 1 n. ${ }^{\circ} 3$ (1793-4) del músico alemán, ${ }^{34}$ según sugiere Torcuato Tejada Tauste. ${ }^{35}$ Situado en el Trío de Beethoven en un entorno métrico ternario y presentado, al unísono, por los tres instrumentos (Ejemplo 1), ese motto abarca cuatro compases, definiéndose por su carácter enérgico basado en dos motivos rítmicos: el primero, de natura-

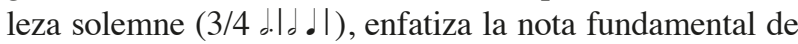
la tónica mediante un grupeto y reiteración tras su paso por la tercera menor superior (do-mib-do); el segundo motivo, más movido merced a la figura de puntillo y corchea (..).।.), despliega un acorde de sexta de la dominante de Do menor reafirmándose su fundamental en el tiempo fuerte del siguiente compás (sił̨-re-sol-sol). ${ }^{36}$

Dicho motto abre la obra de Beethoven al encabezar el primer movimiento en el marco de un pausado pasaje, de diez compases, que tiene un aire de introducción lenta merced a la profusión de silencios y calderones. Este pasaje se detiene, tras la repetición del segundo motivo, transportado a un semitono superior, en un acorde de sexta aumentada sobre el sexto grado de la tonalidad principal (cc. 7-8) que, empleando nuevamente el motivo de puntillo, incrementa la expectativa al retrasar la entrada del acorde de dominante que finaliza esta sección de apertura de manera semicadencial. Este tema introductorio del Trío op. $1 \mathrm{n}$. $^{\circ} 3$ de Beethoven contrasta con el lirismo de los dos grupos temáticos

${ }^{34}$ El Trío con piano op. 1 n. 3 de Beethoven fue una obra muy apreciada en los años sesenta y setenta del siglo XIX también por el público español, según corrobora el hecho de que fuera interpretado en cinco ocasiones por la SCM, la primera vez el 22 de febrero de 1863, en la tercera Sesión (por los fundadores Jesús Monasterio al violín, Ramón Castellano al violonchelo y Juan María Guelbenzu al piano) y la última el 20 de marzo de 1878, en una Sesión Extraordinaria íntegramente dedicada a Beethoven (con Víctor Mireçki al violonchelo); véase Aguado Sánchez, "El repertorio interpretado", pp. 57, 77 y 130.

35 Tejada Tauste, "El Trío con piano", p. 178.

36 Para obtener información detallada en torno a los Tríos op. 1 de Beethoven, véanse Basil Smallman, The Piano Trio. Its History, Technique, and Repertoire (Oxford: Oxford University Press, 1990; Clarendon paperbacks 1992), pp. 48-52; y Alexander L. Ringer, "3 Klaviertrios Es-Dur, G-Dur und c-Moll op. 1 (zusammen mit dem Streichquintett c-Moll op. 104)", en Beethoven. Interpretationen seiner Werke, 2 vols., ed. Albrecht Riethmüller, Carl Dahlhaus y Alexander L. Ringer (Laaber: Laaber, 1994), vol. 1, pp. 1-20. 


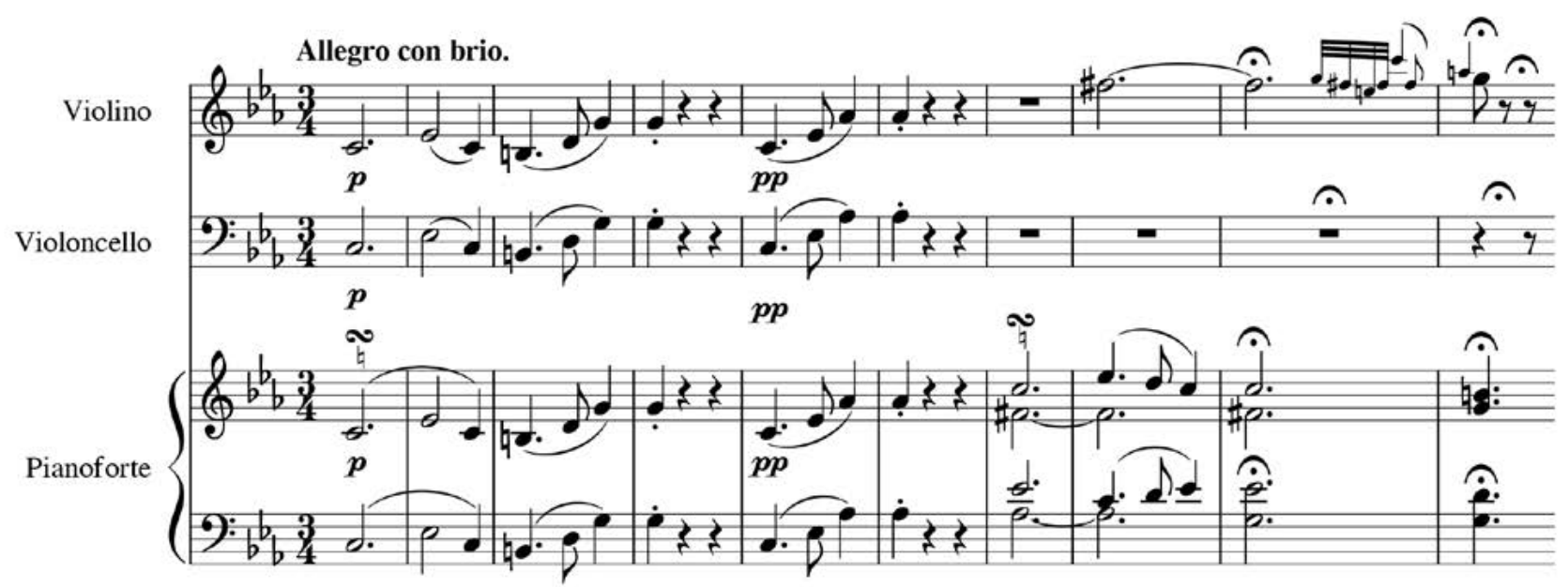

Ejemplo 1. Beethoven, Trío con piano en Do menor op. 1 n. o 3, I, cc. 1-10.

que constituyen la exposición de la forma sonata, a pesar de que el primero deriva diastemáticamente del motivo con puntillo de aquel en su versión final descendente (mib-re$d o-d o-s o l)$, el cual se encuentra reiteradamente citado por el piano con un ritmo anacrúsico de corcheas (cc. 10-12). El propio motto (al igual que el motivo de cabeza del primer grupo temático) tiene de nuevo protagonismo en las secciones tradicionalmente atemáticas, tales como el puente (iniciado en Lab mayor en la exposición, c. 31) y el respectivo grupo final de la exposición (c. 98) y reexposición (c. 303), así como en la sección de desarrollo que será iniciada con una cita del mismo en Mib menor (c. 138). Además, el motto cobra especial relevancia dentro de la reexposición del trío, al emprender - tras una pausa general (c. 225), a continuación de la recapitulación del tema introductorio y en sustitución del primer grupo temático- un denso trabajo motívico (en Do mayor y Reb mayor) de sus dos componentes a través de superposiciones y progresiones cromáticas que conducen a Sol mayor, insinuando así un segundo desarrollo (cc. 226-244).

Frente al planteamiento formal del supuesto modelo beethoveniano, el cual está estructurado en cuatro movimientos, interconectados mediante procedimientos de derivación motívica, Tintorer optó en su cuarteto con piano por una concepción rapsódica de forma durchkomponiert en un solo movimiento al enlazar dos partes contrastantes entre sí en cuanto a agógica y contenidos: ${ }^{37}$ la primera,

${ }^{37}$ La primera edición del cuarteto con piano (Quatuor) de Tintorer llevada a cabo por la casa S. Richault en París no deja lugar a
Andante mosso, en tempo lento (cc. 1-152) y la segunda, Allegro ma non tanto, en tempo rápido (cc. 153-409). Igual que en su trío con piano, Tintorer renunció también en este cuarteto a la forma sonata, ${ }^{38}$ la cual, sin embargo, rige los dos movimientos extremos (I y IV) del Trío op. 1 n. ${ }^{\circ} 3$ de Beethoven. En su lugar, recurrió el músico español a principios formales de repetición y yuxtaposición, en detrimento de procesos orgánicos de desarrollo. ${ }^{39} \mathrm{~A}$

dudas de que se trata de un solo movimiento dividido en dos partes. Lo corroboran las dos barras simples que cierran el Andante mosso (visiblemente diferenciadas de las barras finales tanto en la partitura general como en las partichelas del ejemplar impreso), el enlazamiento inmediato de estas dos partes y el aviso, tras las barras de cierre del Andante mosso (final de la página 2 en la parte de la viola), del cambio de compás (c) que se producirá en el Allegro ma non tanto. No obstante, estas obviedades, la edición moderna, a cargo de Jordi Domènech (Barcelona: Dinsic Publicacions Musicals, S. L., 2009), separa las dos partes de la obra numerándolas con las cifras I y II, respectivamente, insinuando así una estructura en dos movimientos individuales, asumida como tal también por Tejada Tauste ("El Trío con piano", p. 178).

38 Según el análisis de Tejada Tauste, "El Trío con piano", pp. 163-179, la forma sonata no es empleada en ninguno de los tres movimientos del Trío en Fa mayor de Tintorer.

39 La primera parte, Andante mosso, consta de tres secciones contrastantes, precedidas de una introducción:

Introducción (cc. 1-12: Do m) - $A_{1}$ (13-33: Do m) - $A_{1}$ (33-53 = repetición literal $)-$ "puente" (53-59: $\rightarrow$ Sib M) - B (60-79: Solb M) - B (79-99) - C (99-110: Mib M) - C (111-122) - A (123-142: Do $m=A_{1}$ con nuevo acompañamiento $)-$ Coda $(143-152: \rightarrow$ Do M). En el cuarteto de Tintorer no se aprecian analogías motívicas 


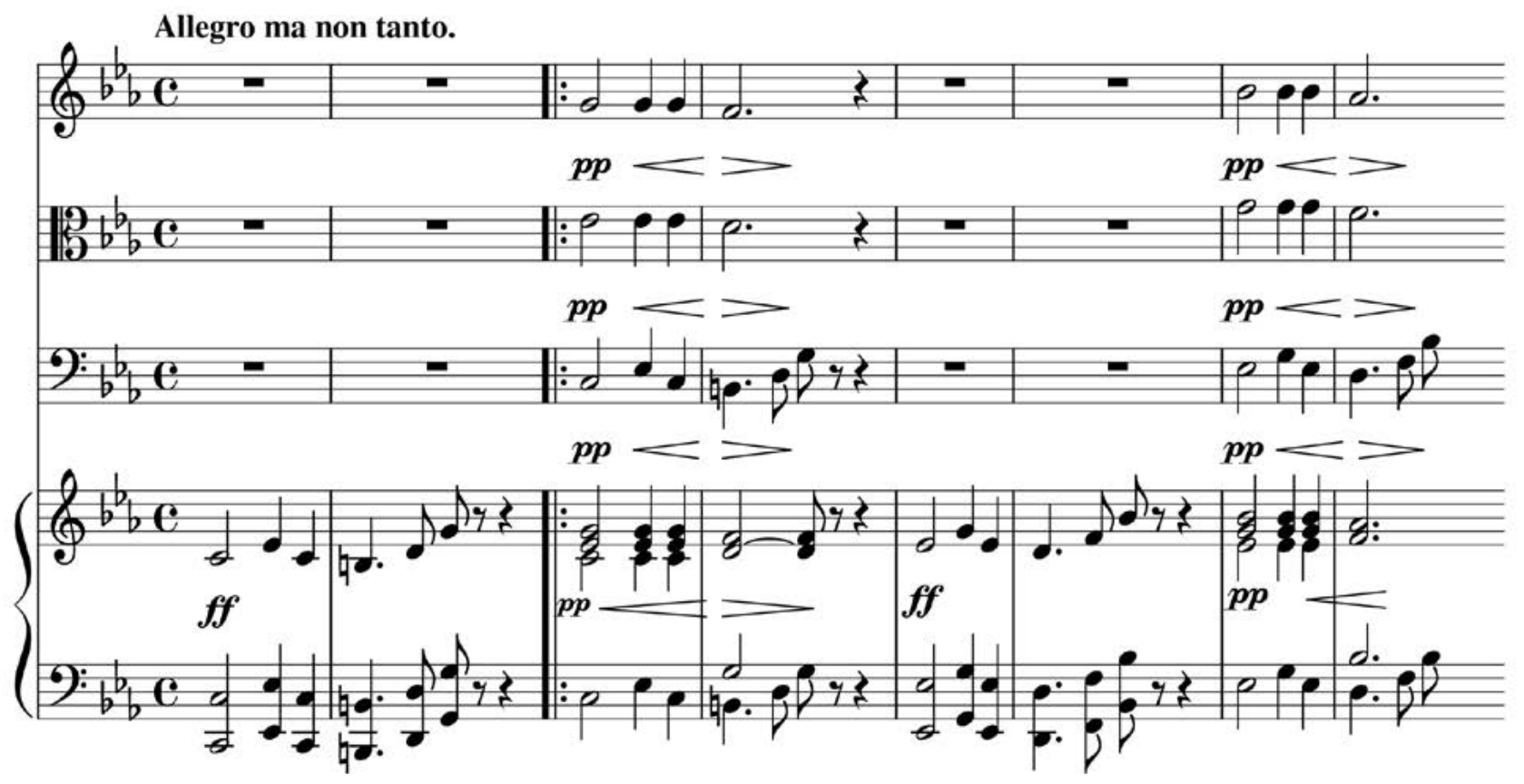

Ejemplo 2. Tintorer, Cuarteto con piano en Do menor, cc. 153-160 (sección A del Allegro). ${ }^{40}$

diferencia de la pieza "recordada" por Tintorer, el aludido "souvenir" de Beethoven no aparece sino en la rápida segunda parte de su cuarteto con piano que se inicia con la cita del motto, literal en cuanto a las alturas y la presentación en unísono (restringido, en este caso, al piano), si bien adaptado a un compás cuaternario (Ejemplo 2).

Como consecuencia de este cambio métrico, la característica reiteración del sonido final queda omitida, garantizándose así que, a semejanza del modelo, la nota conclusiva del motto recaiga sobre un tiempo fuerte del compás. Alternando inicialmente entre el modo menor del patrón original (Do) y su respectivo relativo mayor (Mib) y, a continuación, entre Sib menor y Reb mayor, respectivamente, el motto de dos compases - en vez de conformar una entidad temática cerrada - se repite incesantemente a lo largo de la primera sección del Allegro ma non tanto. En dos ocasiones se complementa con un rápido

entre la parte lenta y la parte rápida; en cambio, el trío con piano cita material del primer movimiento en la coda del finale. Véase Tejada Tauste, "El Trío con piano", pp. 163 y 168-169.

${ }^{40}$ Los ejemplos musicales 2 a 5 se realizaron a partir de la primera edición del cuarteto de Tintorer (París: S. Richault, [ca. 1865]). elemento escalístico ascendente, ornamentado con bordaduras inferiores, para afirmar, a modo de reposo cadencial, las tonalidades de Do menor (cc. 165-166) y Sib menor (171-172). A una inesperada interrupción del discurso musical por medio de una pausa general de un compás ${ }^{41}$ (c. 177) sigue un estático pasaje atemático (cc. 178-182), basado en un acorde de séptima disminuida que conduce a la dominante de la tonalidad principal con el fin de preparar el retorno del motto (c. 183). Iniciado ahora en modo mayor, el motto se encuentra nuevamente secuenciado varias veces a diferentes alturas (Do M, La m, Reb M, Sib m, Lab M), antes de dar paso, mediante un acorde de sexta aumentada, a un estruendoso reposo cadencial, en fortissimo (ff), sobre Sol mayor (cc. 196-202). Su fundamental - al unísono (de tres octavas) - desciende finalmente una quinta por grados conjuntos, para enlazar con la tónica de Do menor coincidiendo con la entrada, en pianissimo $(p p)$, de la segunda sección (c. 204).

${ }^{41}$ La injustificada ruptura del discurso musical mediante una pausa general en el compás 177 del Cuarteto en Do menor de Tintorer (primera edición) ha sido subsanada a través de su omisión en la grabación en CD del Trio Reger y la pianista Maria Victòria Cortés (Sabadell: La mà de guido, 2004). 


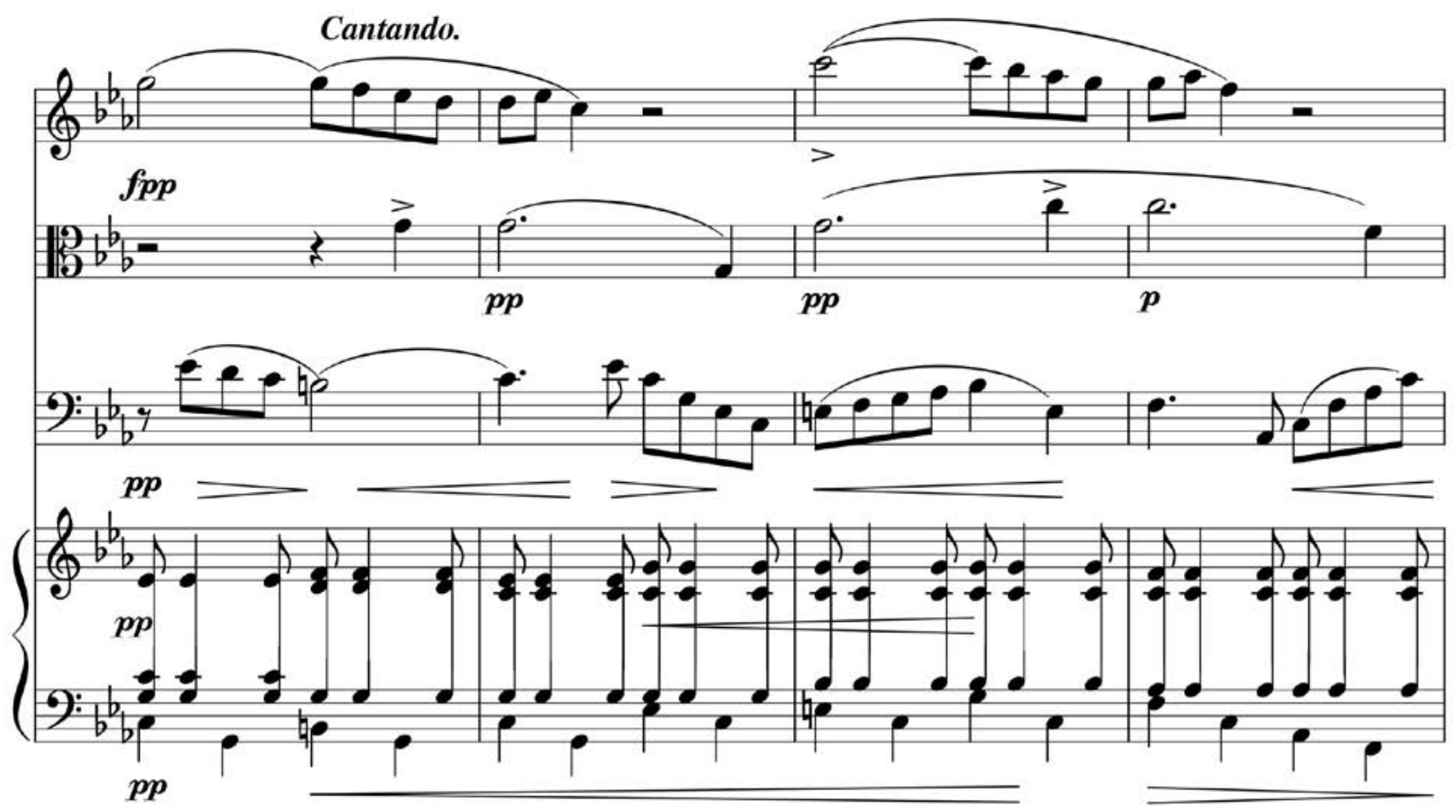

Ejemplo 3. Tintorer, Cuarteto con piano en Do menor, cc. 204-207 (sección B del Allegro).

El carácter enérgico de esta primera sección (A) del Allegro ma non tanto contrasta con el lirismo de las dos secciones siguientes (B y C), en las cuales los tres instrumentos de cuerda ejercitan una densa interacción camerística relegando el piano a un papel de mero acompañamiento. ${ }^{42}$

La sección B (Cantando, cc. 204-247; véase Ejemplo 3) conserva la tonalidad principal de Do menor que será retomada por el motto (cc. 248-251), el cual reaparece fugazmente a través de una doble cita al inicio de un extenso pasaje transitorio con función primero cadencial y luego modulatoria (cc. 248-274) para establecer la tona-

${ }^{42}$ Los contenidos musicales de las secciones A, B y C del Allegro ma non tanto no tienen relación con la parte lenta del cuarteto de Tintorer; la reutilización, en el presente estudio, de estas letras mayúsculas para distinguir las secciones se debe a cuestiones prácticas. En dichas secciones del cuarteto de Tintorer es especialmente reseñable el diálogo emprendido entre el violín y el violonchelo, prácticamente ausente en el Trío en Fa mayor, según Tejada Tauste, donde el violonchelo "tiene un papel casi testimonial, reforzando la armonía”. Véase Tejada Tauste, "El Trío con piano", p. 173. lidad de la sección C (cc. 274-347; véase Ejemplo 4), Solb M, que es la más alejada, en el círculo de quintas, de la tonalidad originaria. ${ }^{43}$

La estructura de las dos secciones líricas obedece a principios de repetición y secuenciación que abarcan tanto el conjunto de las respectivas melodías como destacados motivos de las mismas. Encadenadas - especialmente hacia el final de $\mathrm{C}-$ mediante progresiones descendentes por terceras, dichas secuencias desembocan en la dominante de la tonalidad principal, la cual, tras el restablecimiento de la tónica de Do menor (c. 337), será cuestionada en seguida, antes de su consolidación definitiva. Este retorno de la tónica se produce por medio del motto que inicia la repetición integral de los anteriores 346 compases y -a continuación (o en sustitución) de esta - de la subsiguiente coda (c. 347b), respectivamente.

${ }^{43}$ Comparado con el Cuarteto en Do menor, el Trío en Fa mayor de Tintorer posee un planteamiento tonal mucho más simple que aquel por basarse en tonalidades cercanas, evitándose en mayor medida sonoridades menores (Ibidem, p. 169). 


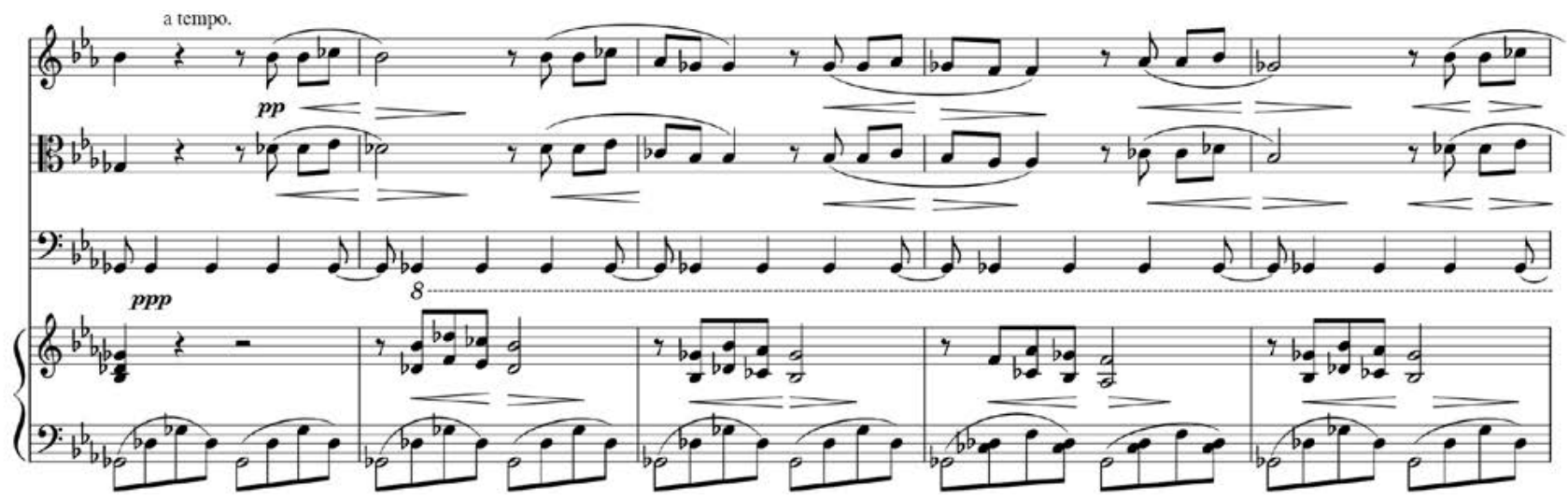

Ejemplo 4. Tintorer, Cuarteto con piano en Do menor, cc. 274-278 (sección C del Allegro).

A pesar de cierta hipertrofia formal que resulta del exceso de reiteraciones y secuenciaciones tanto temáticas como motívicas, el Allegro ma non tanto alberga en sus 194 compases, hasta la doble barra de repetición, rasgos que evocan la exposición de una forma sonata, debido, por una parte, a la oposición -insólita por la distancia de tritono - de las dos regiones tonales imperantes (Do mSolb M) y, por otra parte, al contraste entre el vigor del triádico motto de la sección A y el lirismo de los respectivos temas de las secciones B y C. ${ }^{44}$ Por ello, la posterior aparición de la "Coda" (denominación conforme a la primera edición impresa de la obra) es percibida por el oyente experimentado como la esperada sección central de desarrollo gracias al inicial fugato a distancia de quinta, así como al climax (c. 360) y al intenso trabajo motívico ejecutado a lo largo de cincuenta compases con la participación del motto beethoveniano (cc. 347b-397; véase Ejemplo 5). En este pasaje, el compositor español procede, más allá de sus habituales recursos de secuenciación, a la liquidación motívica y combinación de los compo-

${ }^{44}$ Los procedimientos aditivos de repetición y yuxtaposición suponen una práctica común también en el Trío en Fa mayor, según lo observado por Tejada Tauste, el cual, en su valoración estética de la obra, deduce de la superabundancia de recursos reiterativos "que se trata de una pieza ligera, sin demasiadas pretensiones, fácil de asimilar"; véase Tejada Tauste, "El Trío con piano", p. 166. En su grabación en CD del cuarteto de Tintorer, el Trio Reger y la pianista Maria Victòria Cortés (Sabadell: La mà de guido, 2004) evitan la repetición integral del Allegro ma non tanto hasta la doble barra al enlazar (en la vuelta) el compás 203 directamente con la coda (347b), recapitulando de esta manera únicamente la sección $\mathrm{A}$. nentes del motto con otros elementos, tanto escalísticos como arpegiados.

Omitiendo una eventual reexposición, el cuarteto de Tintorer finaliza con una cadencia plagal en Do menor a continuación de una última cita del supuesto "souvenir" de Beethoven, ejecutado, al unísono, por el conjunto íntegro (cc. 389-399).

De acuerdo con el estado actual de la investigación, el Cuarteto en Do menor de Pere Tintorer puede considerarse - a semejanza de su Trío en Fa mayor $-{ }^{45}$ obra pionera de su género en España, ${ }^{46}$ país periférico en el contexto europeo en cuanto al desarrollo de la música de cámara, con escasísimas aportaciones en el siglo XIX. ${ }^{47}$

45 Conforme a las investigaciones realizadas por Tejada Tauste, "El Trío con piano", p. 163, hasta la fecha el Trío con piano en Fa mayor de Tintorer puede considerarse "el primer representante finalizado dentro de la tradición del género escrito por un compositor español".

46 Para obtener información adicional sobre el desarrollo global del género del cuarteto con piano, véase Basil Smallman, The Piano Quartet and Quintet. Style, Structure, and Scoring (Oxford: Oxford University Press, 1994; Clarendon paperbacks, 1996).

47 Celestino Vila de Forns (1829-1915), Maestro de Capilla de la Catedral de Granada, dejó unos años más tarde dos cuartetos con piano, en Do menor y Mi menor, cada uno de cuatro movimientos, que se editaron en Madrid por A. Romero supuestamente en 1882 y 1885 , respectivamente, y son accesibles en Biblioteca Digital Hispánica; las obras se encuentran grabadas junto con el Gran Quintetto [sic] para piano, 2 violines, viola y violonchelo por miembros del Cuarteto Teixidor y el pianista Santi Riu (Música de Cambra / Celestino Vila de Forns, Barce- 


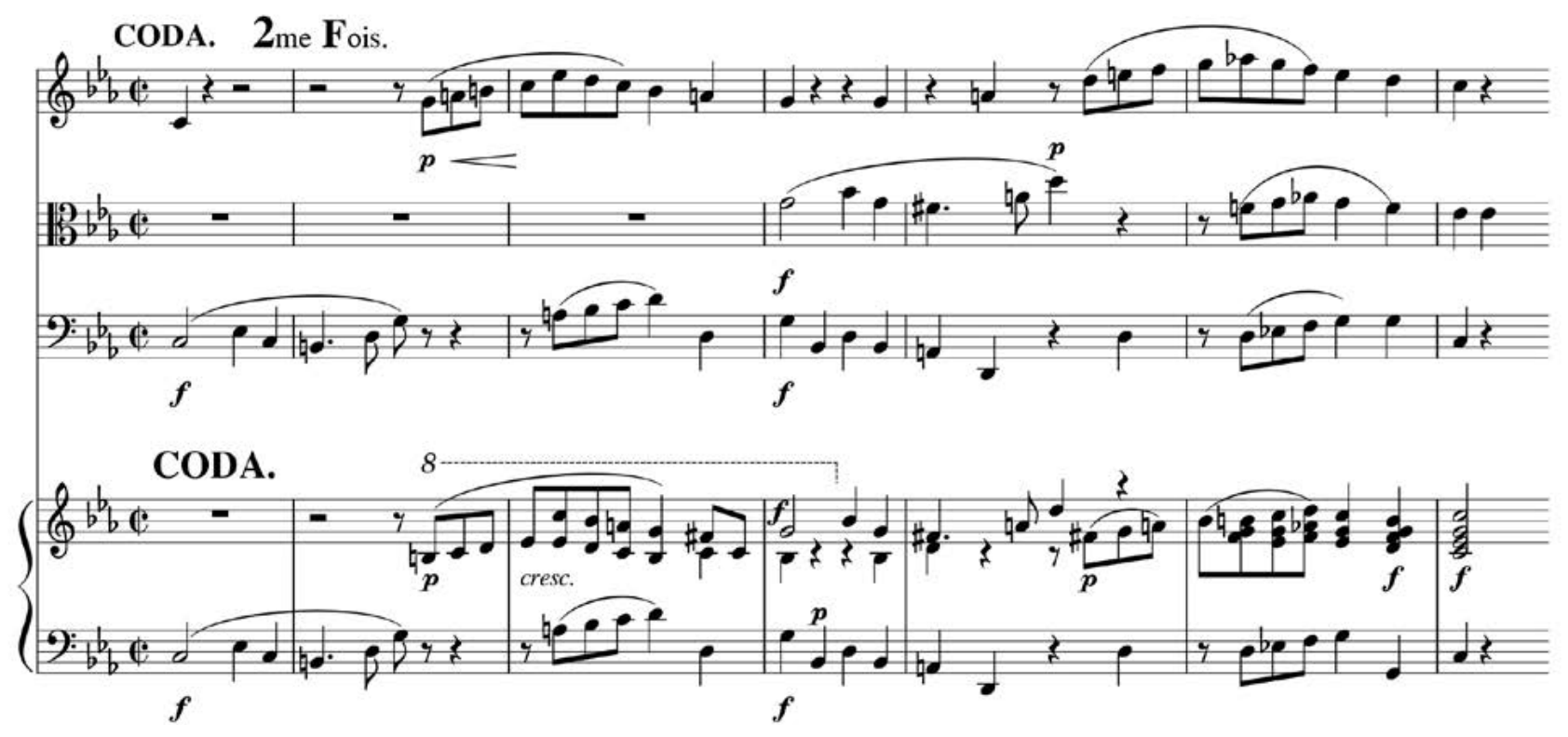

Ejemplo 5. Tintorer, Cuarteto con piano en Do menor, cc. 347b-353 (coda) ${ }^{48}$

La aproximación de Tintorer a Beethoven en esta obra, insinuada por el propio autor por medio del título, se lleva a cabo principalmente a través de la reinterpretación del motivo inicial del Trío con piano en Do menor op. 1 n. . 3, tomado en préstamo por el compositor español, cuyo cuarteto, además, comparte con aquel la tonalidad. ${ }^{49} \mathrm{Au}-$

lona: Columna Música, 2013 [1CM0314]). Cronológicamente le sigue el Cuarteto para violín, viola, violonchelo y piano en Mib mayor (1898) de Juli Garreta (1875-1925), en cuatro movimientos (manuscrito en el Centre de Documentació de l'Orfeó Català en Barcelona, E-Boc, signatura CAT CEDOC 3.2-104); véase la primera edición a cargo de Abili Fort, ed., Juli Garreta. Quartet amb piano (Barcelona: Dinsic, 2008).

${ }_{48}$ En el violonchelo se corrige la errata del compás 347 b de la partitura de la primera edición (París, S. Richault, p. 24), donde el primer motivo del motto está anotado una tercera por debajo de su versión originaria ( $c f$. piano), si bien la correspondiente partichela está correcta al respecto.

49 Refiriéndose a la grabación en CD de obras españolas para piano a cuatro manos del siglo XIX (El piano español a cuatro manos entre 1830 y 1900, Madrid: SEdeM, 2013 [DCD 286 Discan]), Tejada Tauste, "El Trío con piano”, p. 177, subraya que en las Sonatinas de Tintorer "se aprecia también claramente una influencia de Beethoven, sobre todo en la construcción de melodías y en el uso de células breves provenientes de los temas para las zonas de elaboración". sente en la lenta primera parte, este motto impregna la rápida segunda parte del cuarteto, generalmente sin modificar su perfil rítmico-diastemático (salvo cambiando, en ocasiones, al modo mayor), haciendo uso de manera perseverante de la repetición y secuenciación con la excepción de la sección final, designada "Coda", en la cual se aprecian puntualmente procedimientos de un verdadero trabajo motívico que acercan la obra de Tintorer a su modelo. De este le diferencian, esencialmente, la concepción formal, basada en la yuxtaposición y repetición literal de secciones enteras, y la renuncia general a técnicas de variación, tan típicas de Beethoven. La tendencia a liberarse de las convenciones de las formas clásicas, el planteamiento tonal (con preferencia de tonalidades lejanas) y los recursos armónicos empleados (abundancia de dominantes secundarias, acordes de séptima disminuida y de sexta aumentada) son indicadores, conforme a la época, de una estética inclinada hacia el pensamiento romántico que, en momentos puntuales, en efecto, no tiene reparo en recurrir a fórmulas melódicas caducas que a veces rozan la trivialidad. ${ }^{50}$ Finalmente, merece atención la instru-

${ }^{50}$ Entre estas fórmulas melódicas caducas cuentan los rápidos giros cromáticos de los motivos circulares (piano) en la primera parte (cc. 100-104 y 111-114) o las cadenas de trinos ascendentes (violín) combinadas con descensos cromáticos del 
mentación del Cuarteto en Do menor de Tintorer por su tratamiento eminentemente camerístico, mayoritariamente fundamentado en el diálogo entre los cuatro instrumentos y la participación equitativa en el discurso melódico por parte de los ejecutantes, destacando, además, cierto protagonismo del violonchelo y el virtuosismo ocasional tanto del piano como del violín. ${ }^{51}$

Hacia finales del siglo XIX, la figura de Beethoven seguía siendo una fuente de inspiración para la música de cámara española, como demuestra el Cuarteto de cuerda en Mib mayor de Manuel Manrique de Lara (1863-1929), "marino de profesión y músico por devoción". ${ }^{52}$ Finalizada en 1895 y estrenada el 23 de febrero de 1905 por el Cuarteto Francés, la obra, de cuatro movimientos, es la única aportación al género camerístico por parte de Manrique de Lara. El epígrafe -Elegía (26-III-1827) - del segundo movimiento, en tempo Andante sostenuto, parece aludir a Beethoven al incluir su fecha de fallecimiento. ${ }^{53}$ Teniendo en consideración, además, la cita literaria (en alemán) que encabeza el primer movimiento, extraída del poema Nähe des Geliebten (1795) de Johann Wolfgang von Goethe,$^{54}$ se plantea la cuestión de si, además de expresar la admiración de Manrique de Lara por los máximos representantes del clasicismo germánico, el cuarteto

bajo (piano) en la segunda parte (cc. 216-218 y 240-242). A un juicio semejante llegó Tejada Tauste, "El Trío con piano", pp. 166 y 176, en su análisis del Trío en Fa mayor de Tintorer respecto a algunos procedimientos armónicos e instrumentales.

51 También Tejada Tauste, "El Trío con piano", p. 178, realza la "textura puramente camerística" del Cuarteto en Do menor de Tintorer.

52 Autógrafos de partitura y borradores del Cuarteto de cuerda en Mib mayor de Manuel Manrique de Lara se encuentran en la Biblioteca Nacional (E-Mn, signatura M.MANRIQUELARA/42-43), accesibles también en Biblioteca Digital Hispánica. La edición crítica ha sido realizada por Diana Díaz González y el Cuarteto Bécquer, eds., Manuel Manrique de Lara. Cuarteto en Mi bemol para dos violines, viola y violoncello (en estilo antiguo) ([Madrid]: Museo del Romanticismo, 2015). Véase también Diana Díaz González, "El 'Cuarteto en Mi bemol en estilo antiguo' de Manuel Manrique de Lara”, Revista de Musicología, 36/1-2 (2013), pp. 281-308: p. 282.

${ }^{53}$ E-Mn, signatura M.MANRIQUELARA/42, p. 15.

${ }^{54}$ E-Mn, signatura M.MANRIQUELARA/42, p. 1. Nähe des Geliebten (Cercanía del amado), cuarta estrofa, versos $1^{\circ} \mathrm{y}$ $2^{\text {o. }}$ "Ich bin bei dir; du seist auch noch so ferne, / Du bist mir nah!" (Estoy contigo; aunque estés lejano, ¡/ Estás cercano!) [traducción propia]. no contendrá un programa secreto. ${ }^{55} \mathrm{Al}$ contrario que Tintorer en su cuarteto con piano, Manrique de Lara no tomó préstamos motívicos, si bien es cierto que en dicho movimiento lento también optó, al igual que aquel en su cuarteto con piano, por la tonalidad favorita de Beethoven, Do menor. Desde el estreno de la obra, la prensa madrileña se hizo eco de la posible proximidad estilística del Cuarteto en Mib mayor con Beethoven, que se señaló especialmente en relación con los dos movimientos centrales. ${ }^{56} \mathrm{En}$ tiempos recientes, Diana Díaz González ha llegado a concluir, tras un detallado análisis de la obra, que la "influencia beethoveniana" queda reflejada sobre todo en la "elaboración contrapuntística", la cual, a su juicio, es una de las principales características de la composición, junto con la "complejidad rítmica". ${ }^{57}$

\section{HOMENAJE A BEETHOVEN (1926) DE QUINTÍN ESQUEMBRE}

A comienzos del siglo XX las nuevas sociedades musicales siguieron poniendo en el foco de su interés la música de Beethoven, tal como quedó demostrado por José María García Laborda en su minucioso estudio de las actividades, entre 1901 y 1936, de la Sociedad Filarmónica de Madrid (SFM) ${ }^{58}$ La SFM empezó su labor el 4 de noviembre de 1901 con un concierto monográfico dedicado a Beethoven, en el cual el famoso Quatuor Parent de París interpretó sus Cuartetos de cuerda op. 18 n. ${ }^{\circ} 1$,

55 Discrepo con la hipótesis de Diana Díaz González que interpreta el uso de la cita de J. W. von Goethe al comienzo del cuarteto de Manrique de Lara de referencia "a las aspiraciones de Manrique hacia su credo artístico: Wagner", justificando esta hipótesis con el supuesto empleo, en el último movimiento del cuarteto, del "acorde de Tristán” que, en opinión de Díaz, "no deja de ser un significado simbólico"; véase Díaz González, "Introducción al Cuarteto en Mi bemol", en Manuel Manrique de Lara. Cuarteto en Mi bemol, pp. xi-xvi: xvi.

${ }^{56}$ Respecto a la recepción del Cuarteto de cuerda en Mib mayor de Manrique de Lara, Díaz González, "El 'Cuarteto en Mi bemol en estilo antiguo"”, pp. 284-291, recopila numerosas citas de la crítica musical de la época proporcionando las respectivas referencias bibliográficas.

${ }^{57}$ Díaz González, "El 'Cuarteto en Mi bemol en estilo antiguo",, p. 305.

58 José María García Laborda, La Sociedad Filarmónica de Madrid (1901-1936). Contexto histórico y valoración del repertorio, Biblioteca de Investigación y Patrimonio Musical, Serie Francisco Salinas (Vigo: Academia del Hispanismo, 2011). 
op. 59 n. ${ }^{\circ} 1$ y op. $127 .{ }^{59}$ Era el inicio de una serie de seis conciertos, ofrecidos además los días $6,8,11,13$ y 15 de noviembre, que tenían como objetivo presentar al público madrileño por primera vez la integral de los diecisiete cuartetos.$^{60} \mathrm{La}$ integral de los cuartetos sería programada por la SFM en otras tres ocasiones con la participación de intérpretes internacionales: en 1909 (Cuarteto Checo de Praga), 1913 (Rosé-Quartett de Viena) y 1932 (Quatuor Pro-Arte de Bruselas). ${ }^{61}$ Dentro de la música de cámara, el cuarteto de cuerda era el género más escuchado en los conciertos de la SFM (con 432 audiciones), dando preferencia a las obras de Beethoven, "compositor estrella indiscutible de la Sociedad", según García Laborda, por ser el "más interpretado, ya que experimentó 531 audiciones de sus principales obras". ${ }^{62}$ El empeño por parte de la SFM de "dar la posibilidad al público madrileño de conocer las obras de mayor madurez del genio de Bonn, que apenas eran conocidas en España" ${ }^{63}$ fue compartido también por las agrupaciones camerísticas nacionales de nue-

\footnotetext{
59 Este repertorio es el del programa de mano reproducido en García Laborda, La Sociedad Filarmónica de Madrid (19011936), anexo p. 18. Solo unos meses antes, dichos cuartetos habían sido interpretados por primera vez en su conjunto en París, en la Schola Cantorum, igualmente por el Quatuor Parent.

${ }^{60}$ Las fechas las proporciona García Laborda, La Sociedad Filarmónica de Madrid, listado final del anexo, sin paginación. Aprovecho la ocasión para rectificar la información dada por mí misma con respecto a la supuesta primera ejecución de la integral de los cuartetos de cuerda de Beethoven en Madrid atribuida erróneamente al llamado Cuarteto Checo (que sí la interpretó en 1909); véase Heine, "Die zweite Blüte", p. 129. El cómputo de los cuartetos de cuerda de Beethoven incluye la Gran fuga op. $133\left(=\right.$ n. ${ }^{\text {17 }}$ ).

${ }^{61}$ García Laborda, La Sociedad Filarmónica de Madrid (1901-1936), p. 129.

${ }^{62}$ Sorprendentemente, el género más interpretado fue el lied acompañado por piano (con 1269 audiciones) seguido por la música para piano solo (1151 audiciones) que ocupa el segundo lugar delante de la música de cámara. No obstante, la obra camerística más interpretada no fue un cuarteto de cuerda, sino la Sonata para piano y violín en La mayor de César Franck que se interpretó diecisiete veces. Los cuartetos de cuerda más interpretados de Beethoven en los conciertos de la SFM fueron los op. 59 n. ${ }^{\circ} 1-3$ $(15,14,10$ veces) y el op. 132 (13 veces), además de los op. 127 y op. 131. Véase García Laborda, La Sociedad Filarmónica de Madrid (1901-1936), pp. 128, 130, 133 y anexo, p. 11.

${ }^{63}$ García Laborda, La Sociedad Filarmónica de Madrid (1901-1936), p. 94.
}

va creación: el Cuarteto Francés tocó en Madrid entre 1903 y 1906 catorce de los cuartetos de Beethoven (omitiendo los op. 18 n. ${ }^{\circ}$, op. 131 y op. 133) ${ }^{64}$ cuya música de cámara sería la más interpretada también por este conjunto durante su trayectoria de nueve años. ${ }^{65}$ Por otro lado, en Barcelona presentaba el Quartet Renaixement la integral del corpus cuartetístico beethoveniano en el plazo de un mes, entre el 12 de marzo y el 16 de abril de $1916 .^{66}$

Un año antes, en 1915, la recepción de Beethoven en España había experimentado un impulso adicional, de índole literaria, con la aparición de la traducción al castellano (realizada por el futuro Premio Nobel Juan Ramón Jiménez bajo el patrocinio de la Residencia de Estudiantes) del célebre ensayo biográfico Vie de Beethoven (1903) de Romain Rolland; ${ }^{67}$ la publicación fue reseñada por José Subirá. ${ }^{6}{ }^{8}$ Rolland obtuvo el Premio Nobel de Literatura en ese mismo año y es considerado por Hans Heinrich Eggebrecht el promotor de la venera-

\footnotetext{
${ }^{64}$ Fernando Delgado García, "Chapí camerista en su contexto: las series madrileñas del Cuarteto Francés (1903-1911)", en Ruperto Chapí. Nuevas perspectivas, 2 vols., ed. Víctor Sánchez Sánchez, Javier Suárez-Pajares y Vicente Galbis López (Valencia: Institut Valencià de la Música, 2012), vol. 1, pp. $305-$ 330: 320 .

65 El Cuarteto Francés ofreció en los nueve años de su existencia "un total de veintitrés audiciones y diecienueve obras" de Beethoven; véase Beatriz Hernández Polo, "La música de cámara en Madrid a comienzos del siglo XX a través de la prensa periódica: génesis, actividad, recepción y repertorio del Cuarteto Francés (1903-1912)", tesis doctoral, Universidad de Salamanca, 2017, p. 322.

${ }^{66}$ Para obtener información adicional sobre las actividades del Quartet Renaixement (1912-1921), véase el portal web oficial del compositor y violinista catalán Eduard Toldrà (18951962): http://www.eduardtoldrasoler.info/index/life/chronology/1912-1919-the-explosion-of-the-quartet-renaixement [consultado el 14-V-2020].

${ }^{67}$ Romain Rolland, Vie de Beethoven, Vie des Hommes Illustres (París: Librairie Hachette et $C^{\mathrm{ie}}, 1903$ ); Vida de Beethoven, Vidas de Hombres Ilustres, trad. del francés por Juan Ramón Jiménez (Madrid: Publicaciones de la Residencia de Estudiantes, 1915).

68 Jose Subirá, "Leyendo libros. Vida de Beethoven, por Romain Rollan [sic], traducción de Juan Ramón Jiménez", Vida manchega, 5/164 (10-VII-1916), p. 10. En dicha reseña de la publicación de Rolland describe Subirá a Beethoven como "el más puro, más noble y más santo de los artistas".
} 
ción de la figura de Beethoven en Francia en el temprano siglo XX. ${ }^{69}$

El renovado énfasis en la difusión del repertorio camerístico clásico-romántico enfocado en los cuartetos de cuerda de Beethoven dejó sus huellas también en los compositores españoles, incluso en aquellos que estuvieron involucrados de lleno en el (frustrado) proyecto del Teatro Lírico para la creación de la ópera nacional, como los músicos veteranos Ruperto Chapí (1851-1909) y Tomás Bretón (1850-1923) o, de la generación siguiente, Conrado del Campo (1878-1953), este último, de hecho, era buen conocedor de la música de cámara beethoveniana debido a su condición de violista e integrante del Cuarteto Francés. En pleno debate acerca de la ópera nacional, desde principios del siglo XX se observa también en España (al igual que previamente en otros países europeos) un cambio de paradigmas en la música de cámara, la cual se abría cada vez más a la integración de elementos folclóricos provenientes de la música popular, generalmente evitados en el siglo XIX, cuyo uso deliberado puede interpretarse como manifestación artística de la identidad nacional y/o regional. Frente a estas innovaciones relativas al contenido musical, seguían vigentes, en mayor medida, los criterios formales de los modelos clásicos respecto a la organización del material sonoro. No obstante, en comparación con el período anterior parece imperar ahora la influencia de Beethoven (en detrimento de Haydn) que se plasma, entre otros factores, en la ampliación de las dimensiones tanto de la microestructura como de la macroestructura, la priorización de tonalidades menores, la sustitución del Minueto por amplios Scherzos o movimientos con carácter scherzando y la utilización de indicaciones descriptivas en cuanto a tempo y expresión. ${ }^{70}$

${ }^{69}$ Eggebrecht, Zur Geschichte der Beethoven-Rezeption, p. 13. No hay que olvidar el papel de Vincent d'Indy respecto a la recepción de Beethoven en Francia ejercido desde finales del siglo XIX a través de su posición directiva en la Société Nationale de Musique y, al menos desde 1900, mediante su labor pedagógica en la Schola Cantorum. Véase Christiane Heine, "La enseñanza de Vincent d'Indy, del análisis musical a la práctica compositiva: Las Sonatas para violín y piano de Paul Le Flem (1905) y Joaquín Turina (1907-1908)", en Cruces de caminos: Intercambios musicales y artísticos en la Europa de la primera mitad del siglo XX, ed. Gemma Pérez Zalduondo y María Isabel Cabrera García (Granada: Universidad de Granada, 2010), pp. 79-137: 82-85.

70 Para obtener información detallada sobre el desarrollo del cuarteto de cuerda en España en el temprano siglo XX, véase Heine, "Die zweite Blüte", pp. 121-299.
Este arraigo en la tradición clásica queda demostrado, a modo de ejemplo, en el Cuarteto n. ${ }^{\circ} 1$ en Re mayor (1903-4) de Tomás Bretón, estrenado por el Cuarteto Francés en Madrid el 18 de febrero de $1904 .{ }^{71}$ Su rigor formal, densidad contrapuntística con gusto por las entradas en fugato, armonía mediántica, temática generada a través de motivos sucintos y por medio de la derivación contrastante, procedimientos de trabajo motívico-temático y durchbrochene Arbeit, tratamiento equitativo de los cuatro instrumentos, así como la poderosa fuga del finale que incluye recursos cíclicos son, todas ellas, características que remiten a Beethoven, evidenciando una calidad compositiva que Bretón ya no volvería a alcanzar en sus posteriores Cuartetos n. ${ }^{\circ} 2$ en Do menor (1907) y n. ${ }^{\circ} 3$ en Mi menor (1909). ${ }^{72}$

Otro ejemplo significativo de la asimilación de Beethoven lo constituyen los cuartetos de cuerda de Conrado del Campo. ${ }^{73}$ Destacan en su mayor parte por una complejidad textural extrema, perjudicial tanto para la práctica interpretativa como para la edición impresa. ${ }^{74}$ Esa textura es resultado sobre todo de la técnica de variación continua, aplicada desde la macroestructura a las células

${ }^{71}$ El autógrafo del Cuarteto n. ${ }^{\circ} 1$ en Re mayor de Bretón se encuentra en la Real Biblioteca, Palacio Real en Madrid, E-Mp, signatura MUS/MSS/1604[12], y la primera edición apareció en Madrid y Bilbao, Sociedad Anónima Casa Dotesio, [ca. 1904]; la edición moderna está a cargo de Fernando Delgado, Tomás Bretón. Música de cámara para cuerda (Madrid: ICCMU, 2011).

${ }^{72}$ Un detallado análisis de los tres cuartetos de cuerda de Tomás Bretón puede consultarse en Heine, "Die zweite Blüte", pp. 168-174.

${ }^{73}$ Conrado del Campo compuso catorce cuartetos de cuerda en dos períodos de su vida diferentes, entre 1903 y 1913 (nos. 1-8) y entre 1942 y 1952 (nos. 9-14), cuyos autógrafos se encuentran (excepto el n. ${ }^{\mathrm{o}} 2$ que no está localizado), junto con el resto de su legado, en el Centro de Documentación y Archivo (CEDOA) de la SGAE en Madrid (E-Msa); existen reprografías en la Biblioteca de la Fundación Juan March en Madrid (E-Mjm). Para obtener información detallada sobre el primer grupo de cuartetos de Del Campo, véase Heine, "Die zweite Blüte”, pp. 177-196, 212-216 y 223-225.

${ }^{74}$ Véase al respecto John Stokes, "A Critical Edition of Conrado del Campo's String Quartet No. 8, 'At the Death of his Mother' (1913). Defining the Scope of the Critical Process through the Creation of a Musically Viable Score for Interpreters", en The String Quartet in Spain, Varia Musicologica, 22, ed. Christiane Heine y Juan Miguel González Martínez (Berna: Peter Lang, 2016), pp. 583-608. 
más ínfimas con el fin de generar diversidad en detrimento de repeticiones literales, que puede considerarse el principio compositivo por excelencia de este músico. La más conocida de las catorce aportaciones de Del Campo a este género es el Cuarteto n. 5 en Fa menor, Caprichos románticos (1907-8), estrenado en Madrid el 28 de febrero de 1908 por el Cuarteto Francés en la versión original de seis movimientos; ${ }^{75}$ es uno de los pocos cuartetos de un compositor español que se interpretó en los conciertos de la Société Musicale Indépendante de París, el 6 de abril de 1911 por el Quatuor Willaume. Aunque poéticamente inspirado, según el subtítulo, en selectas Rimas de Gustavo Adolfo Bécquer (1836-1870), ${ }^{76}$ la concepción musical puede estar influenciada por el Cuarteto de cuerda en Do\# menor op. 131 de Beethoven. La obra de Del Campo, al igual que la de Beethoven, rompe - en su concepción originaria - con el molde formal clásico y su primer movimiento arranca con un fugato cuyo diseño rítmico e interválico evoca el sujeto de la fuga inicial del supuesto modelo. ${ }^{77}$

El año 1927 marcó un nuevo hito en la recepción de Beethoven en España, igual que en otros lugares europeos ${ }^{78}$ al cumplirse el primer centenario de su fallecimiento, conmemorado en Madrid con numerosas actividades musicales y culturales llevadas a cabo por la SFM y otras asociaciones privadas y públicas; se celebraron, entre otras actividades, tres conciertos populares matinales con la participación de la Orquesta Sinfónica organizados y posteriormente reseñados por el diario $\mathrm{El} \mathrm{Sol} .{ }^{79}$

${ }^{75}$ Del Campo redujo posteriormente el Cuarteto n. ${ }^{\circ} 5$ a cuatro movimientos, motivado probablemente por la crítica recibida a causa de las excesivas dimensiones de la obra tras los estrenos en Madrid (reseñado por Cecilio de Roda) y París (reseñado por Joaquín Turina); véase Heine, “Die zweite Blüte”, p. 185.

${ }^{76}$ La primera edición (partichelas) del Cuarteto n. ${ }^{\circ} 5$, en versión de cuatro movimientos, llevaba por título Caprichos románticos para dos violines, viola y violoncello. Inspirados en algunos momentos de las "Rimas" de Gustavo A. Bécquer (Madrid: UME, 1924).

${ }^{77}$ Un análisis pormenorizado con ejemplos musicales del Cuarteto n. ${ }^{\circ} 5$ de Del Campo, que incluye detalles respecto a la génesis de la obra, puede consultarse en Heine, "Die zweite Blüte", pp. 184-189.

78 Véase al respecto Eggebrecht, Zur Geschichte der Beethoven-Rezeption, pp. 17-25.

${ }^{79}$ García Laborda, La Sociedad Filarmónica de Madrid (1901-1936), p. 133.
Asimismo, el Real Conservatorio de Música y Declamación de Madrid ofreció en torno a la fecha de la muerte de Beethoven - los días 17, 20, 24 y 27 de marzo de 1927cuatro conferencias impartidas por profesores del centro, figurando Del Campo entre ellos con una charla sobre "El cuarteto" musicalmente acompañada por el Cuarteto Francés. ${ }^{80}$

Parece probable que el guitarrista, violonchelista y compositor Quintín Esquembre (1885-1965) ideara su propio Homenaje a Beethoven - tal como reza el título de su Cuarteto de cuerda en Sol menor - en el marco de los preparativos para las celebraciones del primer centenario de la muerte del compositor alemán. ${ }^{81}$ Nacido en Villena (Alicante) en 1885, Esquembre se crió en Madrid, donde recibió su formación musical de manera intermitente, incorporándose en 1911 como Profesor de segunda de violonchelo a la Banda Municipal de Madrid y en 1915 además a la Orquesta Filarmónica de Madrid. ${ }^{82}$ Como concertista de guitarra participó desde 1914 - junto con Miguel Llobet (1878-1938), Daniel Fortea (18781953), Emilio Pujol (1886-1980), Andrés Segovia (18931987) y Regino Sainz de la Maza (1896-1981) - en la "reactivación de la vida guitarrística madrileña", que experimentaría un auge en los años veinte culminando en la creación de la Sociedad Cultural Guitarrística (SCG) en noviembre de $1923 .{ }^{83}$ En agosto de 1925 Esquembre fue nombrado "Profesor de Guitarra para desempeñar la Cátedra de este instrumento en el Instituto-Escuela" creado

\footnotetext{
80 "Centenario de la Muerte de Beethoven", $A B C, 23 / 7.553$ (16-III-1927), p. 26.

${ }^{81}$ Los datos biográficos de Esquembre proceden de Javier Suárez-Pajares, "Quintín Esquembre (1885-1965). Vida y obra de un maestro independiente", Roseta. Revista de la Sociedad Española de Guitarra, 2 (V-2009), pp. 54-99. El cuarteto de Esquembre se conserva en una partitura manuscrita apaisada (12 pentagramas por página), sin fecha y sin firma, con algunas tachaduras, que tiene 29 folios numerados (= 56 páginas de música), más una portada con la siguiente inscripción: "Homenaje a Beethoven" / Cuarteto (Sol menor) / Para dos Violines, Viola y Violoncello / por / Quintín Esquembre. El autógrafo se encuentra en el archivo privado de la familia Esquembre. Una edición crítica no comercial de la partitura y de las partichelas, realizada mediante ordenador por José María López Osa y Fernando López y dedicada a Roberto Esquembre (nieto del compositor), está depositada en E-Msa (signaturas AS-20064 y AS33104).

82 Suárez-Pajares, "Quintín Esquembre”, pp. 64 y 69.

83 Suárez-Pajares, "Quintín Esquembre”, pp. 69 y 73.
} 
poco antes por la SCG.$^{84}$ Aparte de las posibles razones de índole laboral y personal, se sospecha que fue sobre todo "su nerviosismo ante el público", atestiguado tras su muerte por coetáneos suyos, lo que le impidió a Esquembre desarrollar su carrera guitarrística más allá de las fronteras españolas y que fuera la causa por la que desde 1926 dedicara más tiempo a la composición que a la interpretación solista. ${ }^{85}$

Al contrario de otros guitarristas profesionales, Esquembre compuso muy poco para su propio instrumento, si bien evocaba la guitarra mediante la gran orquesta ${ }^{86} \mathrm{Su}$ reconocimiento como compositor se sustenta principalmente en una única pieza, La entrada (1922), escrita originalmente para la fiesta de "Moros y Cristianos" de su pueblo natal, la cual, tras independizarse de su función festera y regionalista, se convertiría en obra de fama nacional que sigue siendo, a juicio de Javier Suárez-Pajares, "uno de los pasodobles más célebres del repertorio", se-

${ }^{84}$ Acuerdo de la SCG trasladado el 31-VIII-1925, citado por Suárez-Pajares, "Quintín Esquembre”, p. 76. Pasaría todavía una década hasta que en 1935 las instituciones republicanas crearan una Cátedra de Guitarra en el Conservatorio Nacional de Música y Declamación de Madrid que fue encomendada a Regino Sainz de la Maza, primero como interino y desde 1947 como numerario; véase Federico Sopeña Ibáñez, Historia critica del Conservatorio de Madrid (Madrid: [s. n.], 1967), pp. 154, 169 y 246.

${ }_{85}$ Suárez-Pajares, "Quintín Esquembre”, pp. 78-79.

86 Según Suárez-Pajares, "Quintín Esquembre”, pp. 81, 84, 87, 90, 92-95, Esquembre no compuso hasta la edad de casi cincuenta años su primera obra para guitarra sola, Vals brillante, dedicada a su discípulo Vicente Gómez quien, se supone, la estrenó en Madrid en noviembre de 1933. Le siguió en los tempranos años 1940 un díptico para guitarra, integrado por Canción playera y Zapateado, que es considerado por Suárez-Pajares "la obra maestra de Esquembre para guitarra sola”. En sus últimos años de vida, Esquembre elaboraba arreglos de obras del repertorio tanto clásico-romántico como contemporáneo de origen nacional (Albéniz, Bretón, Chapí, Chueca, Falla, Lorca, Jiménez y Turina) e internacional (Boccherini, Ipolítov-Ivánov, Schubert y Weber) para tres guitarras (véase lista de obras en p. 93), destinadas al Trío Esquembre integrado por los guitarristas Carmen González Lorenzo, Manuel Hernández y su propio hijo, Miguel Esquembre. La evocación de la guitarra se hace patente en el capricho orquestal Guitarra andaluza, estrenado en 1928 en Madrid, cuyo arreglo para dos guitarras y pequeña orquesta fue renombrado Rapsodia española en 1938, durante la estancia de Esquembre, con la Banda Municipal de Madrid, en Valencia. gún corrobora también un número notable de arreglos diversos..$^{87}$

Esquembre presentó en 1926 su Cuarteto de cuerda en Sol menor a los concursos nacionales de Escultura, Literatura, Música, Grabado y Arte Decorativo, convocados el 13 de julio para "una composición inédita de música de cámara para instrumentos de cuerda", según el punto $2^{\circ}$ de las bases para el Concurso de Música. ${ }^{88} \mathrm{La}$ composición obtuvo una de las dos menciones honoríficas destinadas a las obras enviadas anónimamente bajo el lema "Atenea" y "Tantus labor non sit casus", en conformidad con el diploma expedido por el Ministerio de Instrucción Pública y Bellas Artes el 27 de noviembre de 1926 (Figura 1). ${ }^{89}$

Esta excepcional incursión de Esquembre en el género de la música de cámara se debe, tal vez, a la expectativa de un premio en metálico que pudo constituir la principal motivación para que, a la edad de 41 años, compusiera su único cuarteto de cuerda. Era un hábito muy extendido entre sus contemporáneos, siendo uno de los casos más llamativos el de Del Campo, quien solía participar en concursos de composición hasta una edad muy avanzada..$^{90}$ En el supuesto de que el cuarteto fuera escrito

87 Suárez-Pajares, "Quintín Esquembre”, p. 71.

88 Real Orden del 7 de julio de 1926, publicada en la Gaceta de Madrid, 194 (13-VII-1926), pp. 285-286: 286, referencia bibliográfica recogida de Suárez-Pajares, "Quintín Esquembre", p. 80 .

${ }^{89}$ Gaceta de Madrid, 336 (27-XI-1926), p. 1200. El primer premio, de 2.000 pesetas, fue otorgado a la obra presentada bajo el lema "Isis", de Julián Bautista (1901-1961) — su Cuarteto de cuerda n. $^{\circ} 2$, perdido en uno de los primeros bombardeos sobre Madrid al comienzo de la Guerra Civil española- y, el segundo, de 1.000 pesetas, a la composición con el lema "Aparicio" (sin identificar plantilla) de Jerónimo Oliver Arbiol (18811945). El tribunal estaba formado por Rogelio Villar, Julio Francés, Federico Moreno Torroba y el Secretario de los Concursos Nacionales. El lema "Tantus labor non sit casus" fue utilizado ya con anterioridad en el Concurso de la Festa de la Música Catalana 1919/20 por Josep Maria Benaiges i Pujol (1855-1938) para su Cuarteto en Sol menor que entonces obtuvo el Premi de l'Associació d'Amics de la Música.

90 Véase Heine, "El cuarteto de cuerda en el Concurso Nacional de Música de 1949”, en Joaquín Rodrigo y la música española de los años 40, ed. Javier Suárez-Pajares (Valladolid: Universidad de Valladolid y Editorial Glares, 2005), pp. 149172. Suárez-Pajares, "Quintín Esquembre”, pp. 80 y 83, baraja la posibilidad de que Esquembre se presentara nuevamente en 


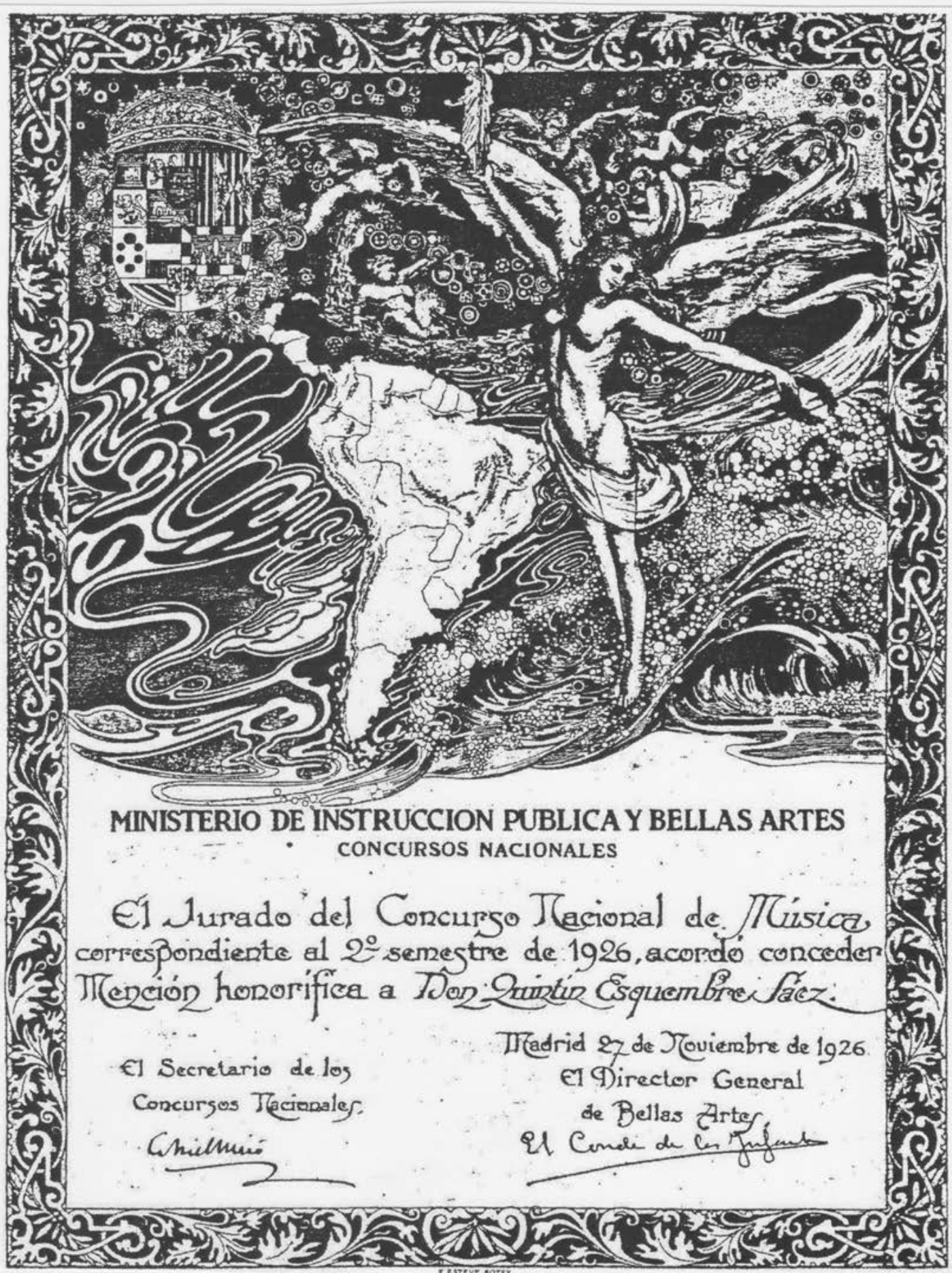

Figura 1. Mención honorífica del Concurso Nacional de Música (1926) concedida al Cuarteto de cuerda en Sol menor de Esquembre. Archivo privado de la familia Esquembre. 
para dicho concurso, cuyo plazo de entrega venció el 30 de octubre de 1926, Esquembre habría dispuesto de tres meses y medio para la concepción y elaboración de la partitura. Tampoco parece descabellado concluir que pretendiera estrenar la obra el año siguiente en uno de los múltiples eventos celebrados con motivo del centenario de Beethoven, tal vez por el Cuarteto Vela, con el cual colaboraba en alguna ocasión. ${ }^{91}$

La partitura del Cuarteto de cuerda en Sol menor incluye una breve nota manuscrita que arroja luz sobre las intenciones compositivas de Esquembre con respecto a su referencia a Beethoven en la portada del autógrafo: evocar - sin necesidad de recurrir a préstamos motívicoslos caracteres de los cuatro movimientos del tradicional cuarteto de cuerda, en consonancia con la estética clásico-romántica del género.

Nota del autor:

Este Cuarteto "Homenaje a Beethoven" no está hecho tomando motivos de sus obras para su realización. He procurado, únicamente, hacer una obra de carácter Severo en su primer tiempo, un Scherzo de sentido Humorístico en el segundo movimiento, en el tercero un Andante de estilo Patético y un Final lleno de Movilidad y Dinamismo.

Esta ha sido mi idea al componerle. ${ }^{92}$

Efectivamente, Esquembre mantuvo la estructura clásica del género, en cuatro movimientos, optando, no obstante, por el modelo más arcaico al situar el Scherzo en el segundo lugar del ciclo: ${ }^{93}$

1928 al Concurso Nacional de Música con una suite orquestal, Estampas de Goya (inédita), que no tuvo suerte, así como en 1951 - a la edad de 66 años - a un concurso internacional celebrado en Milán, en el cincuentenario de la muerte de Giuseppe Verdi, con su única ópera, El príncipe Omar.

${ }^{91}$ Entre otras obras, Esquembre interpretaba con el Cuarteto Vela el Quinteto con guitarra n. ${ }^{\circ} 4$ en Re mayor G.448 de Luigi Boccherini; véase Suárez-Pajares, "Quintín Esquembre, p. 79.

92 Cita literal de la nota manuscrita añadida a la partitura del cuarteto de Esquembre.

93 Beethoven coloca un Scherzo propiamente dicho (Scherzo. Andante scherzoso quasi Allegretto) en segundo lugar solo en uno de sus diecisiete cuartetos, el Cuarteto en Do menor op. 18 n. ${ }^{\circ} 4$ (insólitamente seguido, en tercer lugar, de un Menuetto); características similares aparecen además en los segundos movimientos de los Cuartetos en La mayor op. 18 n. 5 (Minuet) y en Fa mayor op. $59 \mathrm{n}^{\circ} 1$ (Allegretto vivace e sempre scherzando).
I Grave (\lrcorner$=56)$, e, Sol menor / All[ egr $]^{\circ}$ con brio $(\downarrow=138), 3 / 4$, Sol menor, 302 compases

II Scherzo. All[egr $]^{\circ}$ vivace $(.=132), 6 / 8$, Sol mayor, 314 compases

III Elegía. Adagio affettuoso $(\cdot=54)$, c, Do menor, 93 compases

IV Final. All[egr $]^{\circ}$ animato $\left(\downarrow_{=}=138\right), 2 / 4$, Re mayor / Sol menor, 401 compases

En lo que concierne a los tempi, las denominaciones de tres de los cuatro movimientos señalan a Beethoven, quien inició gran parte de sus obras instrumentales cíclicas con un vigoroso Allegro con brio $;{ }^{94}$ ocasionalmente iba precedido por una introducción lenta. ${ }^{95}$ Asimismo, el catálogo de obras de Beethoven contiene numerosos ejemplos de un Scherzo combinado con un tempo Allegro vivace, aunque con menos frecuencia. ${ }^{96}$ En cambio, de entre el amplio abanico de indicaciones de tempo personalizadas con referencia a un determinado estado de ánimo, el título Adagio affettuoso ed appassionato ha sido utilizado por Beethoven solo en una ocasión, para encabezar el emotivo segundo movimiento (en Re menor) de su Cuarteto en $\mathrm{Fa}$

${ }^{94}$ Es el caso de las Sinfonías n. 3 en Mib mayor op. 55 (Eroica) y n. ${ }^{\circ} 5$ en Do menor op. 67, los Conciertos para piano n. ${ }^{\circ} 1$ en Do mayor op. 15, n. $^{\circ} 2$ en Sib mayor op. 19 y n. 3 en Do menor op. 37, los Quintetos de cuerda en Mib mayor op. 4 y en Do menor op. 104, los Cuartetos de cuerda en Fa mayor op. 18 n. ${ }^{\circ}$, en Sib mayor op. 18 n. ${ }^{\circ} 6$ y en Fa menor op. 95, el Trío de cuerda en Mib mayor op. 3, el Trío con piano en Do menor op. 1 n. ${ }^{\circ}$, las Sonatas para piano y violín en Re mayor op. 12 n. ${ }^{\circ} 1$ y en Do menor op. 30 n..$^{\circ}$, la Sonata para piano y violonchelo en Re mayor op. 102 n. ${ }^{\circ} 2$ y las Sonatas para piano en Do mayor op. 2 n. ${ }^{\circ} 3$, en Sib mayor op. 22 y en Do mayor op. 53. Dos sonatas para piano se inauguran con un Allegro molto e con brio (en Mib mayor op. 7 y en Do menor op. 10 n. ${ }^{\circ} 1$ ).

${ }_{95}$ El primer movimiento de la Sonata para piano en Do menor op. 13 (Pathétique) de Beethoven se divide en Grave y Allegro di molto e con brio; por otra parte, los movimientos de apertura de las Sinfonías n. ${ }^{\circ} 1$ en Do mayor op. 21 y n. ${ }^{\circ} 2$ en Re mayor op. 36 de Beethoven comienzan con un Adagio molto seguido del respectivo Allegro con brio; también el Trío de cuerda en Sol mayor op. 9 n. 1 abre con un primer movimiento de Adagio. Allegro con brio.

${ }^{96}$ Los terceros movimientos tanto de la Sinfonía n. 3 op. 55 como de la Sonata para piano en Re mayor op. 28 están denominados Scherzo. Allegro Vivace; su variante ralentizada - Scherzo. Allegretto vivace - conforma el segundo movimiento de la Sonata para piano en Mib mayor op. $31 \mathrm{n}^{\circ} 3$. 


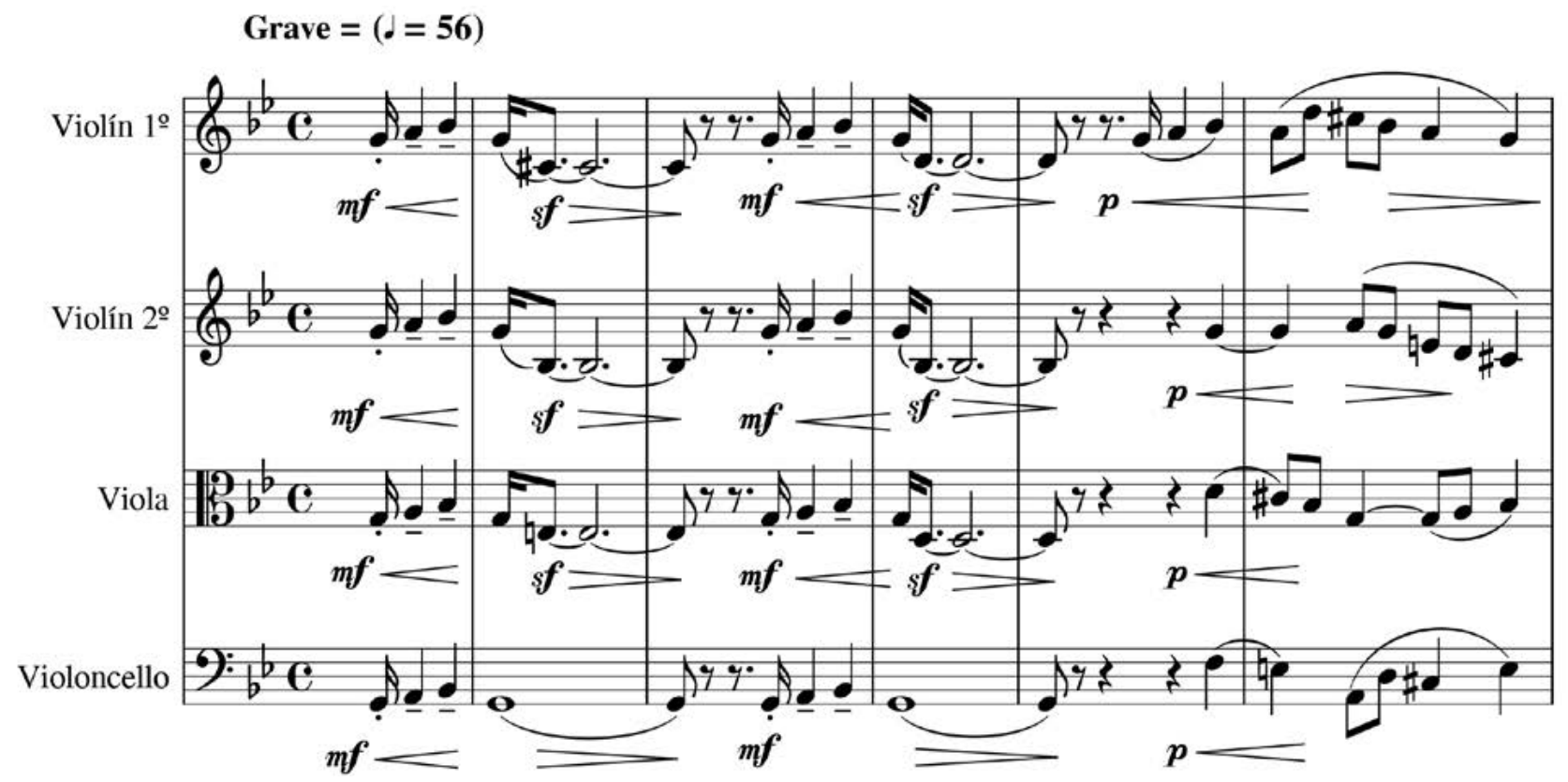

Ejemplo 6. Esquembre, Cuarteto de cuerda en Sol menor, I, cc. 1-5 (introducción lenta) ${ }^{97}$

mayor op. 18 n. 1 (1799-1800). Esquembre se decantó en su Homenaje a Beethoven por una variante abreviada, posponiendo, de hecho, la expresión con passione para indicar su propósito inequívoco de intensificar la tensión desde el compás 14 del movimiento lento..$^{98}$

No obstante la humildad de su autor acerca de sus intenciones, el cuarteto de Esquembre muestra planteamientos formales y procedimientos compositivos que dejan entrever su vínculo con la herencia musical de Beethoven, tal como queda plasmada en la serie de seis Cuartetos de cuerda op. 18 y, en particular, en el mencionado número uno, paradigma estilístico en cuanto al trabajo motívico y uso cíclico de una célula generadora. ${ }^{99}$

${ }^{97}$ Los ejemplos musicales 6 a 12 se han realizado a partir del autógrafo y se reproducen con la autorización de los herederos de Esquembre.

98 Johannes Brahms utilizó la denominación Adagio affettuoso, empleada por Esquembre, para el segundo movimiento de la Sonata para piano y violonchelo n. ${ }^{\circ} 2$ en Fa mayor op. 99 (1886), de la cual, probablemente, el músico español era conocedor en su condición de violonchelista profesional.

99 Para un resumen de las principales características de los seis Cuartetos de cuerda op. 18 de Beethoven, véase Herbert Schneider, "Streichquartette op. 18", en Beethoven. Interpreta-
Esquembre no solamente generó su obra a partir de escuetos elementos rítmico-diastemáticos, sino - de manera similar a su modelo - los empleaba, además, a modo de "motivos de desarrollo" (Entwicklungsmotive), sirviéndose, incluso, de diseños melódicos que forman parte de la tipología básica de Beethoven, tal como quedó definida por Kurt von Fischer. ${ }^{100}$

El cuarteto de Esquembre arranca con una introducción lenta en la tonalidad principal de Sol menor (Grave, cc. 1-20) que presenta un sucinto motivo melódico marcado por el inicio anacrúsico $(\$ . \mid$. $\$)$, el gesto ascendente y el ámbito de tercera menor (Ejemplo 6). ${ }^{101}$ La sucesión

tionen seiner Werke, 2 vols., ed. Albrecht Riethmüller, Carl Dahlhaus y Alexander L. Ringer (Laaber: Laaber, 1994), vol. 1, pp. 133-150.

${ }^{100}$ Kurt von Fischer, Die Beziehungen von Form und Motiv in Beethovens Instrumentalwerken, Collection d'Études Musicologiques, Sammlung Musikwissenschaftlicher Abhandlungen, 30 (Estrasburgo: P. H. Heitz, 1948; 2. a ed. ampliada, Baden-Baden: Valentin Koerner, 1972), pp. 11-16.

101 Solo tres de los diecisiete cuartetos de cuerda de Beethoven comienzan con una introducción lenta: en Do menor op. 59 n. 3 (Introduzione. Andante con moto), en Mib mayor op. 74 (Poco Adagio) y en Mib mayor op. 127 (Maestoso), en este últi- 


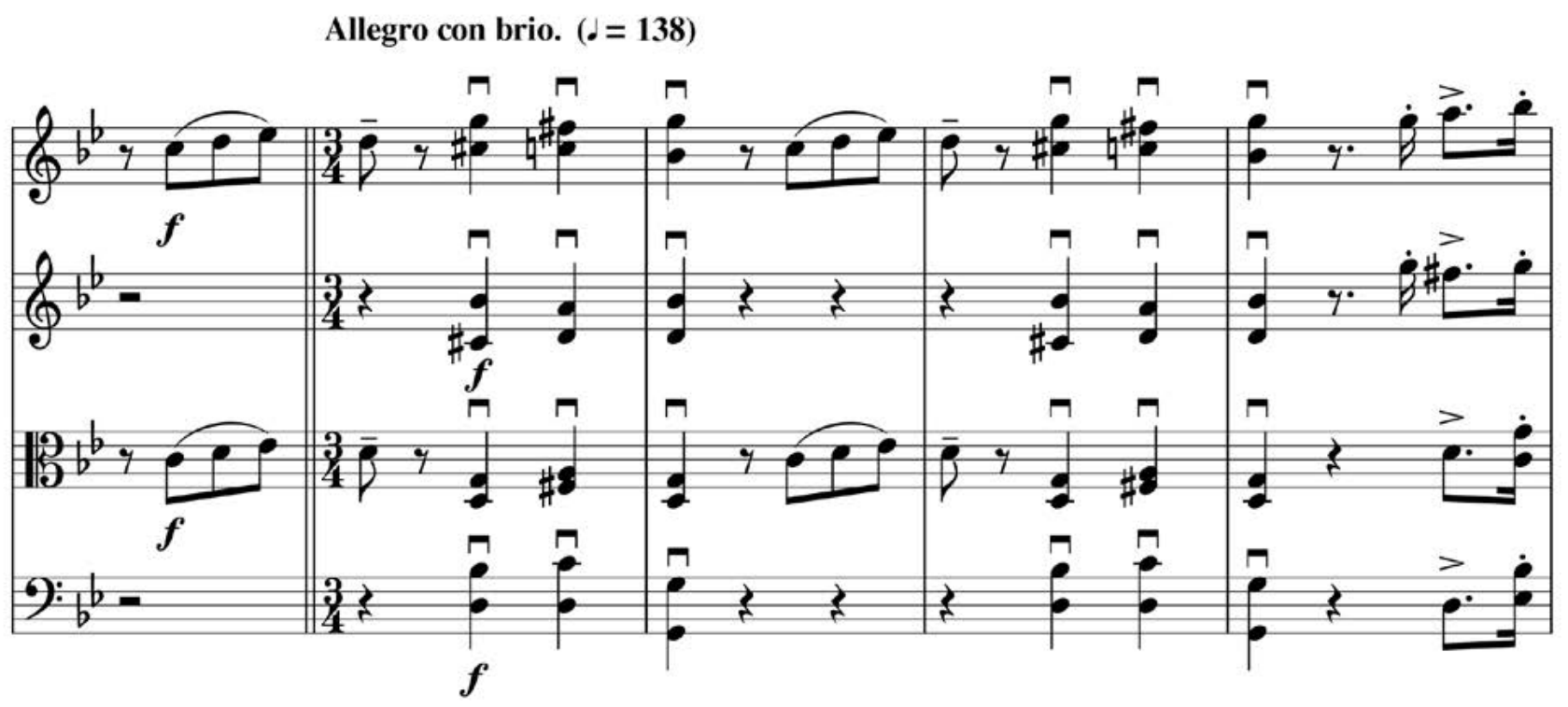

Ejemplo 7. Esquembre, Cuarteto de cuerda en Sol menor, I, cc. 21-24 (1 ${ }^{\text {er }}$ grupo temático) ${ }^{102}$

interválica de segunda mayor-segunda menor (sol-la-sib) resulta ser la "célula generadora" del cuarteto, la cual aporta unidad a la obra al actuar como elemento cíclico, ya que de ella derivan los principales motivos y temas de los cuatro movimientos. ${ }^{103}$

De manera similar al Cuarteto de cuerda en Do mayor op. 59 n. 3 (1804-6) de Beethoven, el objetivo pri-

mo se produce un cambio métrico (de $2 / 4$ a 3/4) al entrar el Allegro tras seis compases. Excepcionalmente, en el Cuarteto en Fa mayor op. 135 se inicia el movimiento final con una introducción lenta (Grave ma non troppo tratto). Sol menor es una tonalidad poco frecuente en la obra instrumental de Beethoven: es tonalidad principal de ninguno de sus cuartetos de cuerda y solamente de una de las treinta y dos sonatas para piano (op. 49 n. ${ }^{\circ} 1$ ), así como de la Sonata para piano y violonchelo op. $5 \mathrm{n} .^{\circ}$ 2; estas dos últimas — de dos y tres movimientos, respectivamente- están encabezadas por un tempo lento (Andante y Adagio sostenuto ed espressivo).

102 En correspondencia con el pasaje análogo de la reexposición (c. 212), se corrige la errata del autógrafo respecto a la viola, que muestra un sib (en lugar de re) en la corchea del compás 3 del Allegro con brio (c. 23 del primer movimiento),

103 Esta "célula generadora" del cuarteto es una variante acortada de la escala diatónica; ambas versiones de la escala (Tonleiterbruchstücke y Tonleitern) están incluidas en la tipología básica de "motivos de desarrollo" de Beethoven; véase Fischer, Die Beziehungen von Form und Motiv, pp. 11-16. mordial de la introducción lenta del primer movimiento de Esquembre, en forma sonata, consiste en crear confusión en el oyente con respecto al centro tonal. Se pone en entredicho, tras el fugaz establecimiento de la tónica de Sol menor (c. 3), por medio de acordes de séptima disminuida y sexta aumentada, la modulación a Re menor (cc. 6-7) y - junto con una aceleración rítmica - las posteriores progresiones ascendentes. La voz superior (violín I) de estas progresiones enfatiza el intervalo de tercera menor hasta llegar a la novena menor ( $m i b$ ) de un acorde de dominante de la tonalidad principal, la cual se asienta definitivamente - después del cambio de compás binario a ternario (3/4) - con la aparición de la tónica en el segundo compás del Allegro con brio (c. 22). A su vez, la sucesión de tres notas contiguas (do-re-mib) - versión transportada de la célula generadora - , reiterada varias veces al final de la introducción por el violín primero, anticipa la configuración rítmico-diastemática que definirá el motivo de cabeza del primer grupo temático de la forma sonata $(\% \ldots .).)^{104}$ El nuevo motivo, completado con re al objeto de resolver la anterior disonancia de novena menor, genera una respuesta complementaria al invertir su característica borda-

104 Parece innecesario señalar que el patrón rítmico de este motivo coincide con el motivo inicial de la Sinfonía n ${ }^{\circ} 5$ en Do menor op. 67 de Beethoven, cuyo primer movimiento, en compás 2/4, es asimismo un Allegro con brio. 


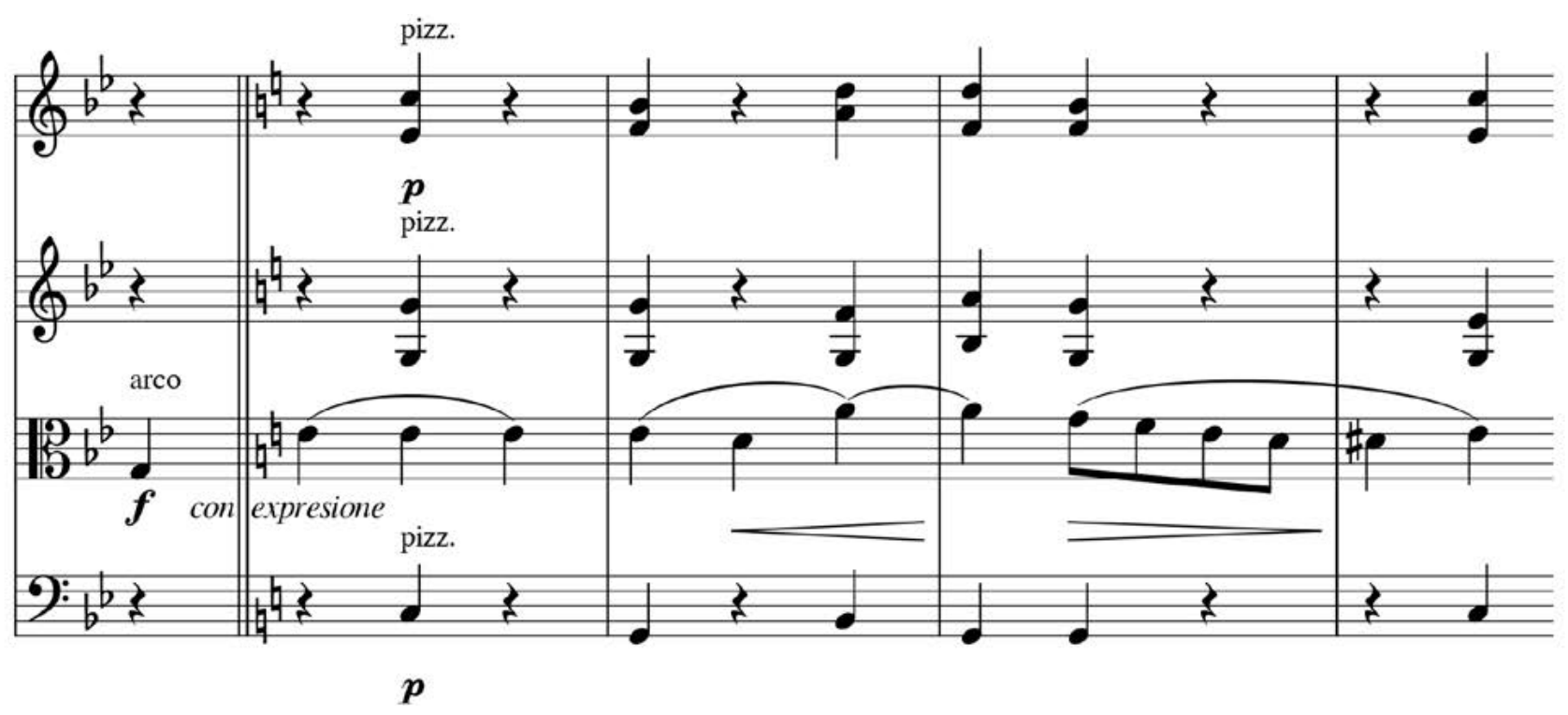

Ejemplo 8. Esquembre, Cuarteto de cuerda en Sol menor, I, cc. 107-110 (2º grupo temático).

dura que se presenta rítmicamente aumentada (๖.」.) y armonizada (Ejemplo 7). ${ }^{105}$

Estas dos células y sus derivaciones dominan el primer grupo temático (cc. 21-106) que se encuentra estructurado en forma lied tripartita (aba'). Su parte central (cc. 59-90) presenta procedimientos de desarrollo distribuidos alternativamente entre los cuatro instrumentos dialogantes, destacando la fragmentación, combinación y superposición motívica en unión con la secuenciación múltiple de dos patrones melódico-armónicos. Dichas secuencias culminan en un climax que se caracteriza por el énfasis en la célula generadora y el estancamiento armónico suscitado por acordes de séptima disminuida. ${ }^{106}$ La siguiente recapitulación parcial (cc. 91-106) del inicio del Allegro con brio, transportado a Sib menor, adopta una función de puente al preparar armónicamente la entrada del segundo grupo temático que se sitúa inusitada-

105 Los motivos de bordadura (Wechselnotenmotive) pertenecen igualmente a la tipología básica de "motivos de desarro1lo" de Beethoven; véase Fischer, Die Beziehungen von Form und Motiv, pp. 32-34.

${ }^{106}$ La utilización de motivos derivados de un tema principal para generar el climax es un procedimiento frecuente también en Beethoven; véase al respecto el capítulo IV.3 "Höhepunktsbildungen" en Fischer, Die Beziehungen von Form und Motiv, pp. 163-176. mente en la región de la subdominante (mayorizada) -Do mayor - respecto a la tonalidad principal.

En comparación con la complejidad textural del primer grupo temático, que resulta de la permanente atomización motívica sustentada por dos células rítmico-diastemáticas, el planteamiento del segundo grupo temático -con expresione [sic] (cc. 107-151) - es mucho más sencillo, al desplegar la viola una tranquila melodía periódica de dieciséis compases, marcada en su comienzo por la anacrusa, la nota repetitiva y el ritmo uniforme de negras (Ejemplo 8) ${ }^{107}$ Este tema se encuentra acompañado por los instrumentos restantes con simples acordes en pizzicato durante su primera aparición (cc. 107-122) y por voces independientes y rítmicamente enriquecidas en la repetición (cc. 123-138), tras ceder el protagonismo al violín primero, duplicado a la octava por el violín segundo en el consecuente.

En sustitución del habitual grupo final, destinado, por lo general, a afirmar la tonalidad secundaria y preparar, en su caso, la repetición de la exposición (omitida en este cuarteto), al segundo grupo temático le sucede un pasaje acórdico de transición (cc. 139-151), armónica-

107 También las repeticiones de notas (Tonrepetitionen) forman parte de la tipología básica de "motivos de desarrollo" de Beethoven; véase Fischer, Die Beziehungen von Form und Motiv, pp. 29-30. 
mente inestable, que modula a Re menor, tonalidad en la cual -después de una extensa pausa general de dos compases - arranca la escueta sección de desarrollo (cc. 152192). Sin recurrir al material del segundo grupo temáti$\mathrm{co}^{108}$ y sin alcanzar un climax, dos series de secuencias, cada una de cuatro compases (Re m, Mib m, Fa m / Sol m, $\mathrm{Sib} \mathrm{m}$ ) evocan las principales células motívicas del primer grupo temático dentro de una textura polifónica que se densifica en la segunda parte. En la transición hacia la reexposición participa nuevamente la célula generadora con el propósito de incrementar la tensión, a través de dos variantes derivadas de la posterior sucesión escalística con ámbito de quinta disminuida ( $f a-s o l-l a b$ / lab-sibdob); esas variantes, alternadas luego con dos pausas generales de tres compases cada una, contribuyen a ralentizar el discurso musical, que se detiene en la dominante de la tonalidad principal (c. 193). Tras un breve silencio, este acorde resuelve en la tónica, coincidiendo con el retorno del Grave que - en contra de la práctica habitual respecto a la forma sonata - inicia la reexposición (cc. 193-283), subrayando el pretendido "carácter Severo" de la pieza. ${ }^{109}$ Aparte de esta repetición inusual de la introducción, lo más destacable de esta última sección es la reducción de sus dimensiones que se debe al recorte de los dos grupos temáticos. Un pasaje cromático conduce a la coda (cc. 291-305), destinada a afirmar la tónica de la tonalidad principal y, a la vez, a evocar repetidamente el motivo de cabeza del Allegro con brio, el cual es citado finalmente, al unísono, por los cuatro instrumentos con objeto de concluir el primer movimiento.

El segundo movimiento del cuarteto de Esquembre, Scherzo. Allegro vivace, en la tonalidad homónima mayor (igual que el Scherzo del Cuarteto en Do menor op. $18 \mathrm{n}$. 4 de Beethoven), se vertebra en torno a los principios compositivos de repetición, variación y yuxtaposición de las partes constitutivas. Aunque de dimensiones beethovenianas, carece de la cohesión formal de su modelo como consecuencia de la ausencia de direccionalidad y de

${ }^{108}$ Lo mismo sucede en el Cuarteto op. 18 n. ${ }^{\circ} 1$ de Beethoven.

109 Beethoven repite la introducción lenta al comienzo de la reexposición solo en su temprana Sonata para piano WoO $47 \mathrm{n}$ o $^{\circ}$ 2 en Fa menor (1782/3); en algún caso aislado retoma la introducción lenta de nuevo antes de la coda, como en la Sonata para piano en Do menor op. 13 (1798), al igual que hizo con anterioridad Joseph Haydn en las Sinfonías n. ${ }^{\circ} 15$ en Re mayor Hob. I:15 (1764) y n. ${ }^{\circ} 103$ en Mib mayor Hob. I:103 (1795). equilibrio tonal. La sección de scherzo (cc. 1-131), estructurada en forma lied tripartita (aba'), parte de una simple melodía de cuatro compases con aire popular. Está rítmicamente marcada por el comienzo acéfalo del grupo de corcheas y la ulterior síncopa $(\% . . . . .1 \%$ ), así como por la doble enunciación de tres notas contiguas, cuyo diseño escalístico deriva de la célula generadora del movimiento anterior, adaptada al compás 6/8 y al modo mayor. Dicha melodía es sostenida inicialmente por un sobrio acompañamiento triádico en ritmo de corcheas picadas, el cual se desintegra más tarde al independizarse las correspondientes voces para tejer un entramado polifónico de densidad cambiante (Ejemplo 9).

El segmento central de la sección de scherzo (cc. 49-102) es armónicamente inestable por proceder, a modo de desarrollo y tras citar la melodía del primer segmento, a la secuenciación de la misma y —en una segunda serie secuencial - a su fragmentación combinada con escalas cromáticas. La posterior sección de trío (cc. 132-180) experimenta un cambio significativo de carácter, motivado, probablemente, por el afán de Esquembre de dotar a la pieza del pretendido "Sentido Humorístico". Este cambio se debe a la sustitución del ritmo ternario del compás $6 / 8$ por un ritmo binario del compás alla breve, el cual se alterna, en el segmento medio, con un compás irregular de amalgama (7/4 con subdivisión 3+4) que es interpretable como un guiño a la música popular. ${ }^{110}$ La recapitulación de la sección de scherzo (cc. 181-272) aparece acortada, modificada y con los segmentos externos intercambiados (a'ba), dando paso, momentáneamente, a una breve cita del trío que le aporta un factor sorpresa (cc. 212-217). La coda (cc. 273-297) despliega por última vez la melodía inicial de aire popular (violín II), cuya cabeza es objeto de un vivaz juego motívico.

110 El compás de amalgama 7/4 forma parte de los ritmos aksak y es usado, por ejemplo, en el folclore castellano, particularmente en ciertos romances. Véase Miguel A. Palacios Garoz, Introducción a la música popular castellana y leonesa (Segovia: Junta de Castilla y León y Excmo. Ayuntamiento de Segovia, 1964), pp. 55-56 y 178 (imagen 41); véase también Alba González Fuentes y Jordi Roquer González, “Amalgama vs. Aksak. About the Conceptualization of Asymmetric Rhythm in Popular Music", El Oido pensante. Portal de Publicaciones Científicas y Técnicas, 4/2 (2016): https://dialnet.unirioja.es/ servlet/articulo? codigo $=5767087$ [consultado el 24-X-2020]. Agradezco a Diego García Peinazo (Universidad de Granada) estas recomendaciones bibliográficas. 


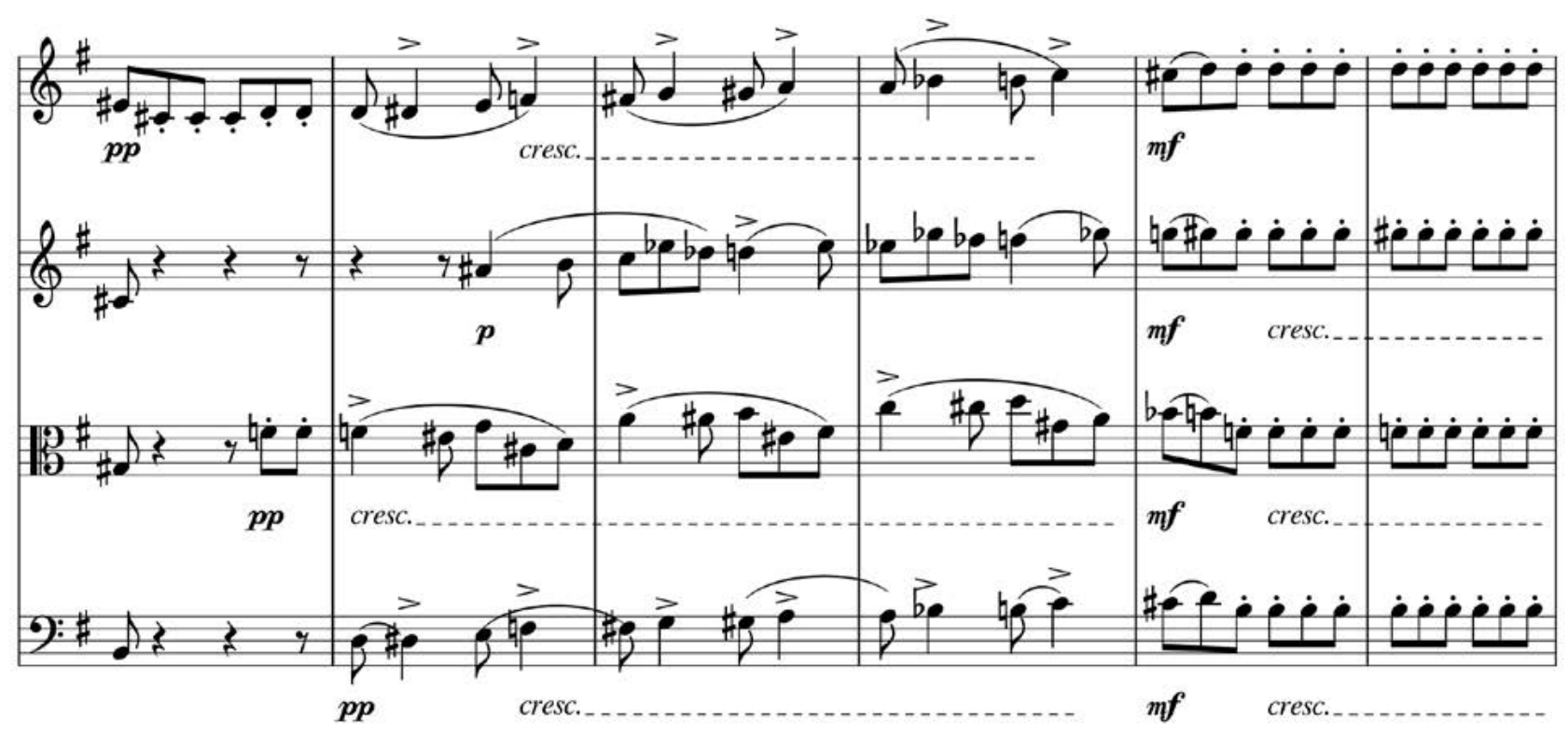

Ejemplo 9. Esquembre, Cuarteto de cuerda en Sol menor, II, cc. 41-46 (scherzo: a).

El título del tercer movimiento, Elegía. Adagio affettuoso, revela las supuestas intenciones de Esquembre, quien adoptó en su homenaje musical a Beethoven recursos estilísticos heredados de la retórica musical de origen barroco con el fin de expresar afectos de dolor y anhelo. No resulta sorprendente que el compositor español eligiera precisamente para el movimiento lento de su cuarteto la tonalidad de Do menor, subdominante menor respecto a la tonalidad de partida. ${ }^{111}$ Esa tonalidad tenía, como es bien sabido, un significado especial para Beethoven a lo largo de su vida y que se suele asociar, en general, a melancolía, tristeza y lamento y, en particular - en relación con el compositor alemán - al patetismo y a la superación del destino. ${ }^{112}$ Aparte del tempo moderado $(.=54)$, la dinámica suave y la tendencia a valores rítmicos largos que marcan sobre todo los finales de las frases melódicas, queda patente el carácter elegíaco de la pieza desde los primeros

111 Según las observaciones de Schneider, "Streichquartette op. 18", pp. 137-138, la subdominante constituye la relación tonal de contraste preferente de Beethoven en los seis Cuartetos de cuerda op. 18 y determina los movimientos lentos de los op. 18 nos. 2,5 y 6.

112 Para obtener información adicional al respecto, véase Benet Casablancas, "Las tonalidades y su significado. Una aproximación”, Quodlibet, 2 (1995), pp. 3-18. compases merced a una expresiva melodía ascendente (cc. 1-5) que será citada, por último, en la posterior coda (cc. 92-97). Cantada en pianissimo ( $p p$ ) por el violonchelo, esta melodía enfatiza el intervalo de tercera; por lo tanto, es derivable de la célula generadora de la obra al igual que el acompañamiento de tresillos complementarios en las voces medias (Ejemplo 10). Este antecedente melódico es contestado, en el presunto consecuente, sobre el quinto grado por el violín primero, el cual abandona rápidamente la tonalidad principal para moverse hacia regiones tonales remotas; modula de Do menor a su relativo mayor Mib $\mathrm{M}$ (cc. 6-9) y luego - utilizando el idéntico patrón armónico en la repetición - de Mib menor a Solb mayor (cc. 10-13). Al mismo tiempo despliega el violonchelo sobre un ritmo solemne de blancas una nueva célula motívica, semitonal y descendente (do-si, sib-la; mib-re, reb-do), que fue introducida previamente en el compás 3 por el violín segundo (mib-re) a modo de retardo.

Estas sucesiones de dos sonidos y sus variantes ampliadas e invertidas poseen una fuerte carga semántica al evocar el clásico "motivo de suspiro" (Seufzermotiv), el cual forma parte de la tipología básica de motivos de desarrollo de Beethoven. ${ }^{113}$ Empleado en este movimiento tam-

113 Véase Fischer, Die Beziehungen von Form und Motiv, pp. 7-11. 

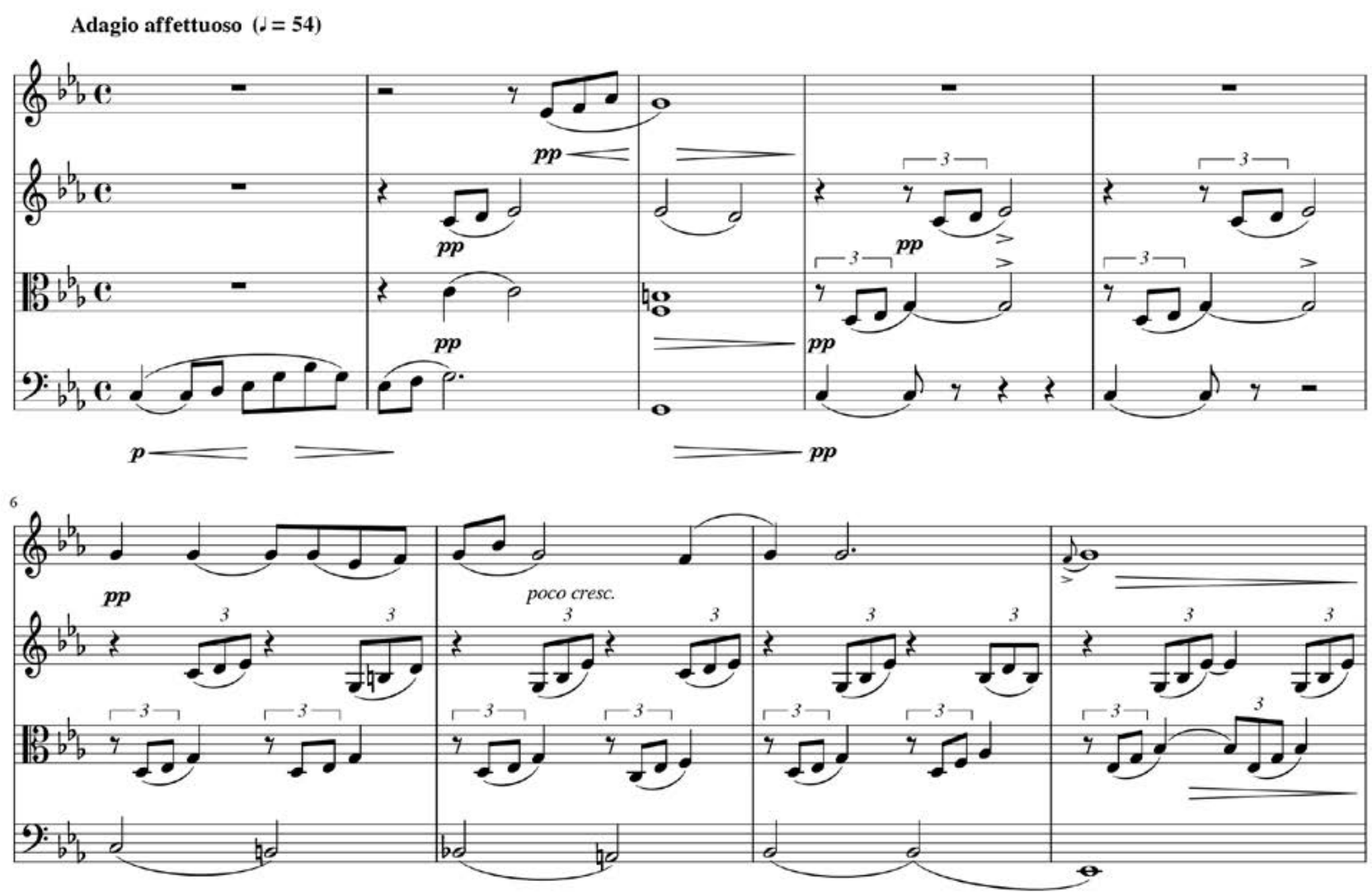

Ejemplo 10. Esquembre, Cuarteto de cuerda en Sol menor, III, cc. 1-9 (sección A).

bién por Esquembre como "medio de intensificacion"114 preferente, dicho motivo de suspiro desempeña un papel importante en el posterior transcurso de la pieza. Es el caso del pasaje denominado con passione (c. 14-21), dentro de la primera sección de la forma lied tripartita (aba'), donde - ubicado, durante ocho compases, en el entorno armónico de la dominante de Mib menor - adopta diferentes diseños rítmico-diastemátios, enriquecidos mediante apoyaturas ascendentes, que forman parte de un agitado juego motívico entre los cuatro instrumentos. Breves pausas expresivas, intercaladas entre estos motivos, así como el paulatino ascenso del violín primero en combinación con crescendi contribuyen a incrementar la tensión. ${ }^{115} \mathrm{El}$ primer

114 Corresponde al término Steigerungsmittel utilizado por von Fischer, Die Beziehungen von Form und Motiv, p. 9.

115 Considerando el trasfondo semántico de esta Elegía, las pausas expresivas desempeñan una función similar a la de la figura retórica barroca suspiratio. climax de esta Elegía se produce con la entrada de la tónica de Mib menor (c. 22) a través de la cita del consecuente melódico, en registro agudo (violín I), combinado nuevamente con un descenso cromático del bajo (violonchelo). Este, no obstante, se prolonga ahora hasta la cuarta (de mib a sib), en representación de una de las figuras retóricas más relevantes de la música occidental desde hace varios siglos, el passus duriusculus, sinónimo musical de lamentación, que volverá a pronunciarse - siempre en unión con la respectiva melodía del violín primero- al comienzo y al final de la posterior recapitulación de esta sección (cc. 76-78 y 88-90). ${ }^{116}$ En comparación con la anterior, la sección central del movimiento lento, Stesso tempo (cc. 25-67), contrasta notablemente a causa del cambio de metro a un com-

116 Para profundizar en la temática del passus duriusculus, véase, por ejemplo, Dietrich Bartel, Musica Poetica. Musical-Rhetorical Figures in German Baroque Music (Lincoln y Londres: University of Nebraska Press, 1997). 


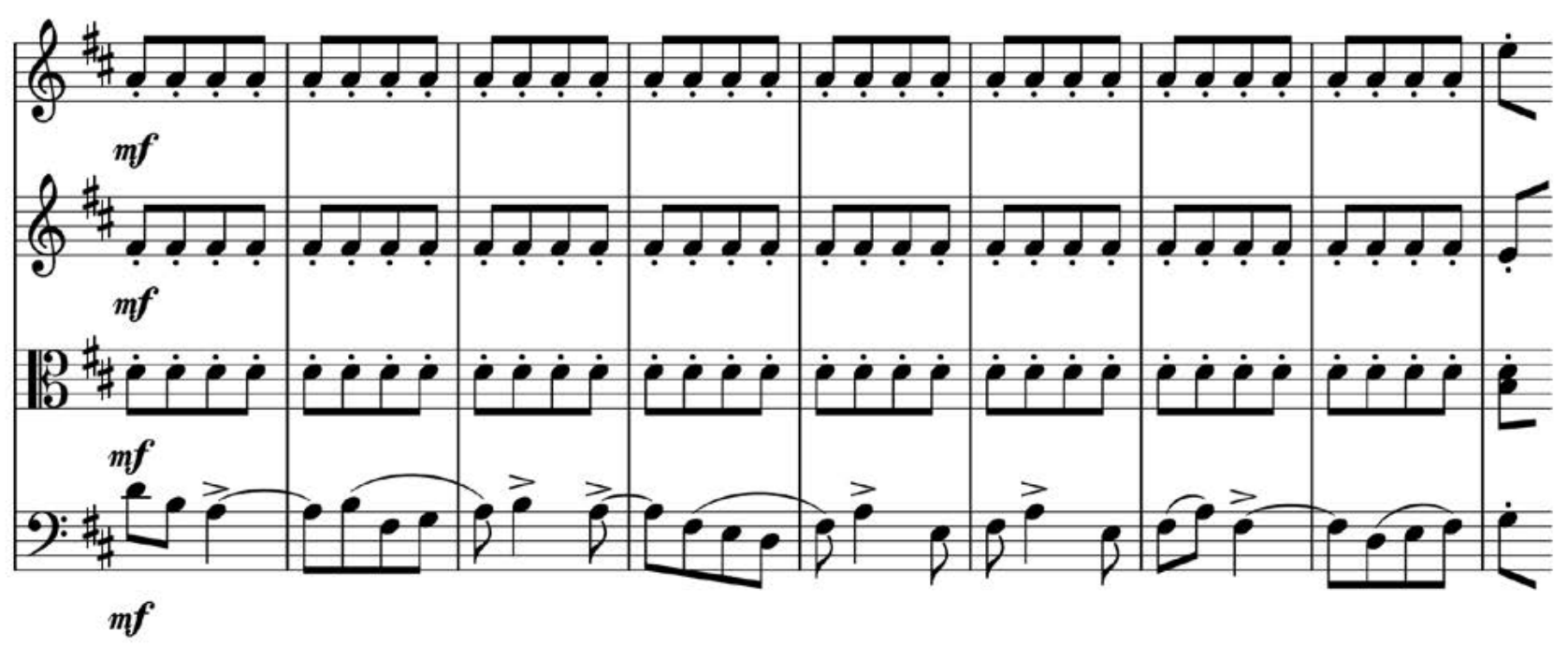

Ejemplo 11. Esquembre, Cuarteto de cuerda en Sol menor, IV, cc. 9-17 (sección A).

pás ternario (3/4) y del ostinato rítmico de síncopas en las voces medias que crean un ambiente animado y actúan como soporte armónico. ${ }^{117}$ Sobre este fondo del acompañamiento, el violín primero desenvuelve una melodía anhelante (cc. 29-45), inicialmente entrecortada por silencios, la cual - en diálogo con el violonchelo- se repite íntegramente, tras un compás de reposo, transportada del inicial Mib menor a Solb menor y del posterior Sib menor a Do menor (cc. 47-67). Dicha melodía asciende gradualmente a través de la triple secuenciación de su primera frase hasta alcanzar el punto álgido (sib y do, respectivamente), apoyándose en el motivo de suspiro, cuyo énfasis en las respectivas sensibles repercute en la armonía al provocar fricciones semitonales. ${ }^{118}$

Después de esta emotiva pieza lenta, "de estilo Patético" conforme a lo anunciado por Esquembre, el último movimiento de su cuarteto, Final. Allegro animato, exhibe un carácter alegre y desenfadado, lleno, efectivamente, "de Movilidad y Dinamismo" que se manifiesta en una estructura libre, ajena a las convenciones formales de

117 Motivos rítmicos basados en síncopas desempeñan un papel importante en la obra de Beethoven como medio usado para acrecentar la tensión y fomentar la fluidez; véase Fischer, Die Beziehungen von Form und Motiv, pp. 52-53.

118 Este diseño melódico tiene su raíz en los conceptos de Leittonmelodik y Sequenzmelodik, según fueron aplicados en el clasicismo vienés por Beethoven y sus contemporáneos. la tradición clásico-romántica. Comparado con los movimientos anteriores, este último tiempo pone más empeño en el trabajo motívico-temático y la variación continua que en la armonía, la cual ostenta una mayor estabilidad y moderación en esta pieza final por moverse dentro de regiones cercanas a la tonalidad principal (Sol menor). Este movimiento, fundamentado en el principio aditivo de yuxtaposición, está compuesto de dos secciones contrastantes que se repiten sucesivamente tras su exposición, la primera sección de manera literal y la segunda abreviada y modificada (ABA'B'+coda). La sección inicial (A), inusitadamente en la tonalidad de la dominante, Re mayor (cc. 1-75), se vertebra en torno a una sencilla melodía con aire de pasodoble (cc.9-16), presentada por el violonchelo tras ocho compases introductorios y acompañada por un bordón triádico de la tónica sobre corcheas picadas (Ejemplo 11). Los primeros tres compases de la melodía abarcan las principales ideas rítmicas de esta sección que serán desarrolladas a continuación mediante modestos juegos motívicos y secuenciaciones. Entre estos motivos destaca nuevamente la síncopa (cc. 11, 13 y 14) que actúa como nexo de unión entre las secciones al impregnar también la sección contrastante. ${ }^{119}$

La segunda sección (B), Stesso tempo, en Sol menor (cc. 76-225) - más extensa y compleja que la primera-

119 El gusto de Esquembre por la síncopa se manifiesta también en su célebre pasodoble La entrada. 
Presso tempo.

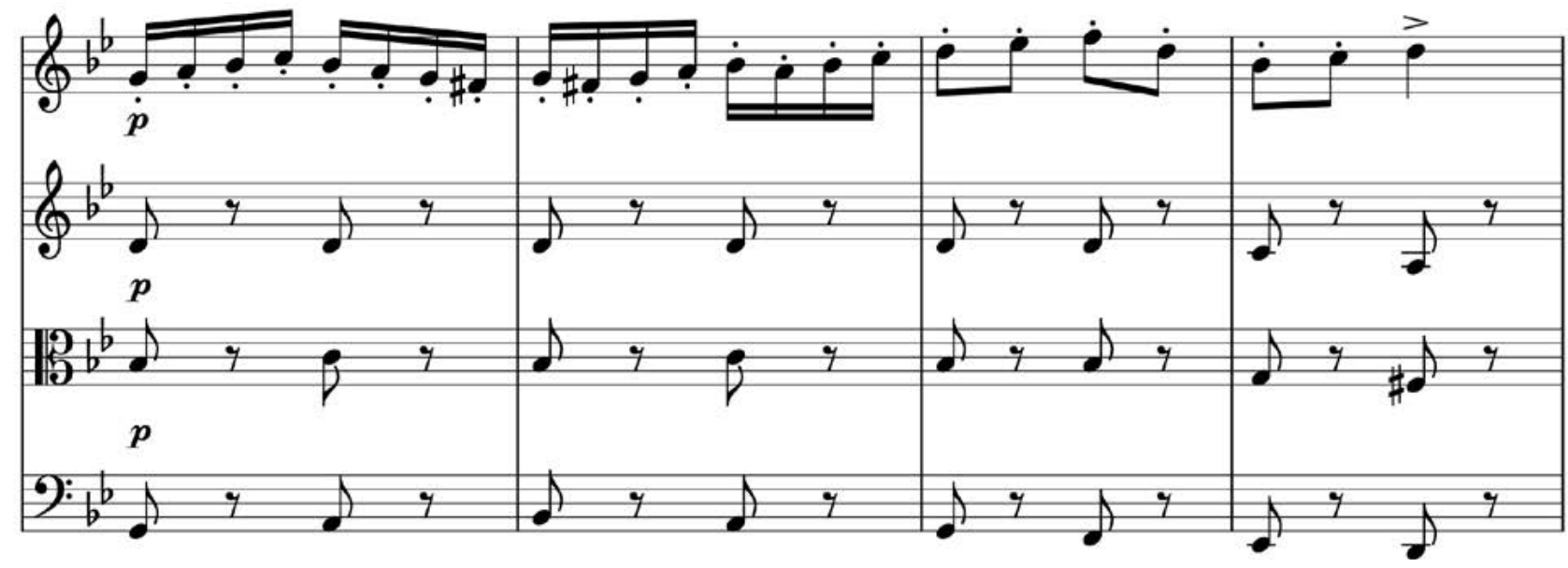

Ejemplo 12. Esquembre, Cuarteto de cuerda en Sol menor, IV, cc. 76-79 (sección B).

parte asimismo de una sencilla melodía de ocho compases, armonizada con tríadas sobre un ritmo entrecortado (Ejemplo 12). Esta melodía, que resulta ser menos cantable que la anterior, se caracteriza por la alternancia de dos frases definidas mediante el ritmo, cada una de dos compases: una rápida, de semicorcheas y con diseño circular, ${ }^{120}$ y la otra más pausada, de corcheas, que alude a la célula generadora del primer movimiento.

En la posterior recapitulación de la segunda sección (B'), dicha célula generadora - elemento unificador del cuarteto de Esquembre - es objeto de un vivaz juego contrapuntístico entre los cuatro instrumentos que conduce al climax, enfatizado por el violín primero mediante la reiteración insistente de la sucesión interválica originaria (do-re-mib) en registro agudo (cc. 316-322). Precedido de un breve stretto (c. 380-386), el cuarteto cierra con un vigoroso pasaje homofónico, destinado a recalcar la tónica de Sol menor - tonalidad principal de la obra - en combinación con un nuevo patrón rítmico, al estilo lombardo, que concede el protagonismo rítmico a la síncopa.

El homenaje brindado a Beethoven en el cuarteto de cuerda de Quintín Esquembre va más allá de las pretensiones admitidas por su autor - de recrear los caracteres de los cuatro movimientos según la tradición-, al cons-

${ }^{120}$ Motivos circulares (kreisende Motive) cuentan entre la tipología básica de "motivos de desarrollo" de Beethoven, quien las utilizó preferentemente en sus movimientos finales; véase Fischer, Die Beziehungen von Form und Motiv, pp. 34-35. truirse la obra a través de diminutos diseños rítmico-diastemáticos arraigados en el clasicismo vienés. Derivados en su mayoría de un germen primario considerado célula generadora, estos elementos se comportan de manera similar a los "motivos de desarrollo" de Beethoven — de acuerdo con la tipología propuesta por Kurt von Fischer - por configurar motivos y temas, aumentar o disminuir la tensión, preparar los puntos álgidos y trazar los fines de segmentos y secciones. No obstante, la priorización unilateral, de parte de Esquembre, de los procedimientos de trabajo motívico repercute en la envergadura de los temas, algunos con aire popular, que tienden a exhibir un aspecto fragmentario e inacabado por atenerse a la presentación de una breve idea melódica, seguida de repeticiones y secuenciaciones de la misma en sustitución de una elaboración temática. La iteración casi obstinada de melodías sucintas, ejecutada, por lo general, dentro de un rígido marco métrico ligado a una tenaz periodicidad clásica ( $4+4$ compases) no deja de producir cierta sensación de monotonía, siendo esta una de las principales características relativas a la arquitectura de este cuarteto. Por otro lado, hay que valorar los efectos que el intenso trabajo motívico tiene sobre el tratamiento camerístico al fomentar el diálogo entre los instrumentos, proclives a emparejarse, uniéndose muy a menudo los registros exteriores y las voces medias, respectivamente. La armonía del cuarteto de Esquembre - repleta de acordes de séptima disminuida, dominantes secundarias y extensas cadenas modulatorias empleadas sin rumbo discernible - es 
plenamente tonal, aferrada a un romanticismo algo trasnochado y ajena a las sonoridades ásperas y atrevimientos armónicos de su tiempo, puestas en práctica, en esa misma época, por coetáneos suyos. ${ }^{121}$

\section{LOS HOMENAJES MUSICALES DE TINTORER Y ESQUEMBRE}

Los cuartetos objeto del presente estudio de Tintorer y Esquembre constituyen una importante contribución a la historia de la recepción de Beethoven en España por ofrecer claros testimonios de la admiración de sus autores por el músico alemán a cuya memoria rinden expreso homenaje. Esta admiración, además de manifestarse de manera evidente a través de los pertinentes títulos de ambas obras y además - en caso de Esquembre - de aclaraciones adicionales, se hace palpable, según quedó demostrado en este estudio, a través del uso de determinados recursos y procedimientos compositivos que resultan por un lado de la apropiación, mediante cita, de un selecto elemento compositivo (Tintorer) y, de otro, de la asimilación intrínseca de criterios estilísticos y formales beethovenianos (Esquembre). A pesar de haber sido concebidos con un intervalo de aproximadamente sesenta años, los dos cuartetos comparten, además de la intención creadora, su arraigo en el lenguaje musical clásico-romántico. No obstante, el apego a sonoridades decimonónicas es discutible en lo que respecta a Esquembre, quien alrededor de 1926 - en pleno apogeo del neoclasicismo - se mostraba indiferente a las corrientes estéticas e innovaciones armónicas de su tiempo.

En sus respectivos homenajes, los dos músicos españoles llevaron a cabo su aproximación a Beethoven -insinuada por los propios autores - de manera complementaria, al poner el foco de atención prioritariamente o en aspectos formales, como Esquembre, o en los contenidos musicales, como Tintorer. Este último rehuyó en su cuarteto con piano las convenciones estructurales de la tradición occidental en cuanto a la música de cámara, al optar por una forma libre en un solo movimiento, del tipo durchkomponiert. En compensación de este distanciamiento de índole formal, Tintorer puso en relación su presente - en torno a 1865 - con el pasado del músico homenajeado a través de uno de los procedimientos intertextuales de mayor cala-

121 Sirve de ejemplo el Concerto para clavicémbalo y cinco instrumentos (1926) de Manuel de Falla, obra clave del neoclasicismo español. do en la historia de la música desde hace siglos, utilizado en el Allegro ma non tanto, segunda parte de la obra, así como en la coda final: ${ }^{122}$ la cita de un escueto motivo que remonta al Trío con piano op. 1 n. 3 de Beethoven, del cual, incluso, asume su tonalidad, Do menor. Adaptado al contexto métrico del cuarteto y reiterado perpetuamente, dicho préstamo musical se impone a modo de motto recordatorio, sin apenas experimentar cambios sustanciales de su configuración rítmico-diastemática, ubicándose en un entorno formal algo distorsionado, imperado por la yuxtaposición de varias secciones contrastantes. El trabajo motívico-temático queda relegado a la sección final (coda), en la cual, más allá de las anteriores repeticiones y secuenciaciones del motivo prestado, el motto beethoveniano es objeto de un verdadero desarrollo que se distribuye de manera equitativa entre los cuatro instrumentos.

A diferencia del cuarteto con piano de Tintorer, el cuarteto de cuerda de Esquembre asimila en tres de sus cuatro movimientos los principios formales heredados de la tradición clásico-romántica, suscitando, además, los respectivos caracteres de cada uno, conforme al propósito de su autor. Por otro lado, la organización del material sonoro obedece a procedimientos constructivos que apuntan hacia el modelo, plasmándose en un notable trabajo motívico y una textura mayormente camerística. Entre los recursos empleados por Esquembre para trazar los temas y motivos destaca el uso de una sucinta célula generadora, verdadero elemento cíclico que desempeña una función unificadora entre los cuatro movimientos al estar presente en la mayor parte de los componentes constitutivos de la obra. Algunos de estos componentes forman parte de la tipología básica de motivos de desarrollo de Beethoven, como el motivo de suspiro, los motivos circulares, escalísticos y de bordadura, así como el motivo rítmico de la síncopa. Un momento culminante, lleno de afecto y pasión, según las indicaciones de tempo en el autógrafo, se produce con la aparición del elegíaco movimiento lento (III) que recurre al método semántico para homenajear al universal músico alemán al utilizar destacadas figuras retórico-musicales de origen barroco.

Resumiendo los resultados analíticos del presente estudio, cabe concluir que el impacto del fervor por Beetho-

122 Para más información sobre procedimientos intertextuales en la creación musical, véase Yvan Nommick, "La intertextualidad: un recurso fundamental en la creación musical del siglo XX”, Revista de musicología, 28, 1 (2005), pp. 792-806. 
ven en el estilo de composición de Tintorer y Esquembre es mayor en el cuarteto de cuerda de este último, aunque - debido a sus sutilezas constructivas - indudablemente menos apreciable por parte del oyente que en el cuarteto con piano de Tintorer que se beneficia al respecto gracias a la tenacidad del citado motto beethoveniano. Aparte de la importancia de las dos aportaciones para la historia de la recepción de Beethoven en España, las dos obras ocupan un lugar diferente en el contexto de la respectiva historia de la composición de su tiempo. La relevancia del Cuarteto con piano en Do menor de Pere Tintorer radica en el hecho de que - de acuerdo con el estado de la investigación actual - se trata de una obra pionera por suponer la primera contribución conocida al género en España en el siglo XIX, la cual, además, goza de un tratamiento eminentemente camerístico, sin parangón en la música de cámara española hasta la supuesta fecha de creación, salvo en su propio Trío con piano en Fa mayor. Por el contrario, el Cuarteto en Sol menor de Quintín Esquembre - incursión única de su autor en la música de cámara - se ubica en el contexto de la producción cuartetística española del temprano siglo XX, asumiendo las tendencias de la época en lo referente a este género musical. De gran envergadura, la obra respeta las convenciones formales, prioriza las tonalidades menores, ofrece un extenso Scherzo y evoca, además, en dos de los cuatro movimientos (II y IV), la música popular como concesión estética al nacionalismo musical imperante.

Recientes aportaciones a la música de cámara acreditan que, desde la perspectiva de la composición, el interés en Beethoven no ha menguado en las últimas décadas entre los músicos españoles, según corroboran sendas obras para cuarteto de cuerda de Alfredo Aracil $(* 1954)$ y Benet Casablancas $(* 1956)$. Aspirando a la unidad de forma y contenido, ambos recurren, de manera independiente, al Cuarteto en Sib mayor op. 130 (en seis movimientos) de Beethoven para extraer material sonoro con el fin de reinterpretarlo dentro de un contexto musical moderno. ${ }^{123}$ Gracias a estos procedimientos intertex-

${ }^{123}$ Aracil asimila en Cuarteto 2 (1991) una célula ínfima de la Cavatina, quinto movimiento del op. 130 de Beethoven; véase Alfredo Aracil, "More than Composing for 4 Instruments", en The String Quartet in Spain, Varia Musicologica, 22, ed. Christiane Heine y Juan Miguel González Martínez (Berna: Peter Lang, 2016), pp. 785-803: 789-794. Casablancas somete el motivo inicial del Andante con moto, ma non troppo, tercer movimiento del op. 130, a múltiples transformaciones en Widmung (2016-7); véase Benet Casablancas, “Componer para cuarteto tuales, de escribir "música sobre música", anticipados por Tintorer en la música de cámara española del siglo XIX y cultivados en el marco de la música contemporánea desde finales del siglo XX, la recepción de Ludwig van Beethoven a través de la creación artística continúa siendo actual en nuestros días, mucho más allá de los grandes aniversarios.

\section{FUENTES PRIMARIAS}

Esquembre, Quintín. "Homenaje a Beethoven" / Cuarteto (Sol menor) / Para dos Violines, Viola y Violoncello / por / Quintín Esquembre, autógrafo (sin fecha y sin firma), archivo privado de la familia Esquembre; edición crítica no comercial (partitura y partichelas), realizada por José María López Osa y Fernando López (E-Msa, signaturas AS-20064 y AS-33104).

Tintorer, Pere. Un / souvenir de L. van Beethoven / Quatuor / pour / Piano, Violon, Alto et Basse / dédié à / M.r F. Frontera de Valdemosa / Professeur de Chant de S. M. la Reine Isabelle II / par P. Tintorer. París: S. Richault, [ca. 1865].

- Quartet en Do menor per a violí, viola, violoncel i piano, editado por Jordi Domènech. Barcelona: Dinsic Publicacions Musicals, S. L., 2009.

\section{BIBLIOGRAFÍA CITADA}

Aguado Sánchez, Ester. "El repertorio interpretado por la Sociedad de Cuartetos de Madrid (1863-1894)". Música. Revista del Real Conservatorio Superior de Música de Madrid, 7-9 (2000-2002), pp. 27-140.

Allen, Aaron S. "Beethoven as 'Pianista'? The Reception of Beethoven's Piano Music in Italy through the 1860s". Arietta. Journal of the Beethoven Piano Society of Europe, 8 (2014), pp. 48-60.

Aracil, Alfredo. "More than Composing for 4 Instruments". En The String Quartet in Spain. Varia Musicologica, 22, editado por Christiane Heine y Juan Miguel González Martínez. Berna: Peter Lang, 2016, pp. 785-803.

Bartel, Dietrich. Musica Poetica. Musical-Rhetorical Figures in German Baroque Music. Lincoln y Londres: University of Nebraska Press, 1997.

de cuerda hoy: la música de cámara en estado puro", en Ibidem, pp. 805-829: 826-828. 
Brzoska, Matthias. "Beethoven der Gekreuzigte: Aspekte frenetischer Beethoven-Rezeption in Frankreich". Archiv für Musikwissenschaft, 71/2 (2014), pp. 85-98.

Casablancas, Benet. "Las tonalidades y su significado. Una aproximación”. Quodlibet, 2 (1995), pp. 3-18.

_ . "Componer para cuarteto de cuerda hoy: la música de cámara en estado puro". En The String Quartet in Spain. Varia Musicologica, 22, editado por Christiane Heine y Juan Miguel González Martínez. Berna: Peter Lang, 2016, pp. 805-829.

"Centenario de la Muerte de Beethoven", $A B C, 23 / 7.553$ (16-III-1927), p. 26.

Cuenca, Vicente. "Sociedad de Cuartetos". El Artista, 1/26 (30-XI-1866), pp. 4-5.

_. "Sociedad de Cuartetos". El Artista, 3/35 (22-II1868), pp. 181-184.

Delgado García, Fernando. "Chapí camerista en su contexto: las series madrileñas del Cuarteto Francés (1903-1911)". En Ruperto Chapí. Nuevas perspectivas, 2 vols., coordinado por Víctor Sánchez Sánchez, Javier Suárez-Pajares y Vicente Galbis López. Valencia: Institut Valencià de la Música, 2012, vol. 1, pp. 305-330.

Diaz González, Diana. "El 'Cuarteto en Mi bemol en estilo antiguo' de Manuel Manrique de Lara”. Revista de Musicología, 36/1-2 (2013), pp. 281-308.

_. "Introducción al cuarteto en Mi bemol". En Manuel Manrique de Lara. Cuarteto en Mi bemol para dos violines, viola y violoncello (en estilo antiguo), editado por Diana Díaz González y el Cuarteto Bécquer. [Madrid]: Museo del Romanticismo, 2015, pp. xi-xvi.

Eggebrecht, Hans Heinrich. Zur Geschichte der Beethoven-Rezeption. Spektrum der Musik, 2. Laaber: Laaber, 1972; nueva edición completada, 1994.

- Musik im Abendland. Prozesse und Stationen vom Mittelalter bis zur Gegenwart. Munich: Piper, 1991; edición de bolsillo revisada, 1996.

Fischer, Kurt von. Die Beziehungen von Form und Motiv in Beethovens Instrumentalwerken. Collection d'Études Musicologiques / Sammlung Musikwissenschaftlicher Abhandlungen, 30. Estrasburgo: P. H. Heitz, 1948; 2. a edición ampliada, Baden-Baden: Valentin Koerner, 1972.

Fournier, Bernard (en colaboración con Roseline Kassap-Riefenstahl). Histoire du quatuor à cordes, 3 vols., Paris: Fayard, 2010.

Gaceta de Madrid, 194 (13-VII-1926), pp. 285-286.
Gaceta de Madrid, 336 (27-XI-1926), p. 1200.

García Laborda, José María. La Sociedad Filarmónica de Madrid (1901-1936). Contexto histórico y valoración del repertorio. Biblioteca de Investigación y Patrimonio Musical / Serie Francisco Salinas. Vigo: Academia del Hispanismo, 2011.

García Velasco, Mónica. "La Sociedad de Cuartetos de Madrid (1863-1894)". Cuadernos de Música Iberoamericana, 8-9 (2001), pp. 149-193.

González Fuentes, Alba, y Jordi Roquer González. "Amalgama vs. Aksak. About the Conceptualization of Asymmetric Rhythm in Popular Music". En El Oído pensante. Portal de Publicaciones Científicas y Técnicas, 4/2 (2016): https://dialnet.unirioja. es/servlet/articulo?codigo $=5767087$ [consultado el 24-X-2020].

Heine, Christiane. "El cuarteto de cuerda en el Concurso Nacional de Música de 1949”. En Joaquín Rodrigo y la música española de los años 40, editado por Javier Suárez-Pajares. Valladolid: Universidad de Valladolid y Editorial Glares, 2005, pp. 149-172.

_. "La enseñanza de Vincent d'Indy, del análisis musical a la práctica compositiva: Las Sonatas para violín y piano de Paul Le Flem (1905) y Joaquín Turina (1907-1908)". En Cruces de caminos: Intercambios musicales y artísticos en la Europa de la primera mitad del siglo $X X$, editado por Gemma Pérez Zalduondo y María Isabel Cabrera García. Granada: Universidad de Granada, 2010, pp. 79-137.

- "Streichquartettkomposition in Spanien im 19. Jahrhundert: eine inexistente Gattung?". En The String Quartet: From the Private to the Public Sphere. Speculum Musicæ, 27, dirigido por Christian Speck. Turnhout: Brepols, 2016, pp. 333-369.

_. "Die zweite Blüte: Spanische Streichquartettproduktion im frühen 20. Jahrhundert". En The String Quartet in Spain. Varia Musicologica, 22, editado por Christiane Heine y Juan Miguel González Martínez. Berna: Peter Lang, 2016, pp. 121-299.

Heine, Christiane, y González Martínez, Juan Miguel, eds. The String Quartet in Spain. Varia Musicologica, 22. Berna: Peter Lang, 2016.

Heine, Christiane. "Introducción". Marcial del Adalid (1826-1881). String Quartet in G major op. 58 / Cuarteto de cuerda en Sol mayor op. 58. 19th-Century Spanish String Quartets / Cuartetos de cuerda españoles del siglo XIX, editado y dirigido por 
Christiane Heine. Madrid: Ediciones Eudora S. L., 2017, pp. 11-14.

-. "Introducción". Salvador Giner (18321911). String Quartet No. 1 in G major / Cuarteto de cuerda N..$^{\circ}$ en Sol mayor. 19th-Century Spanish String Quartets / Cuartetos de cuerda españoles del siglo XIX, editado y dirigido por Christiane Heine. Madrid: Ediciones Eudora S. L., 2017, pp. 11-14.

-. "Introducción". Salvador Giner (1832-1911). String Quartet No. 2 in G major / Cuarteto de cuerda N. 2 en Sol mayor. 19th-Century Spanish String Quartets / Cuartetos de cuerda españoles del siglo XIX, editado y dirigido por Christiane Heine. Madrid: Ediciones Eudora S. L., 2017, pp. 11-14.

Hernández Polo, Beatriz. "La música de cámara en Madrid a comienzos del siglo XX a través de la prensa periódica: génesis, actividad, recepción y repertorio del Cuarteto Francés (1903-1912)”. Tesis doctoral, Universidad de Salamanca, 2017.

J. V. R. "Sociedad de Cuartetos". Revista y Gaceta Musical, 1/51 (22-XII-1867), p. 275.

Krabbe, Niels. "The Reception of Beethoven in Copenhagen in the 19th Century". Musik Forskning, 21 (1995), pp. 160-210.

Kraus, Beate Angelika. Beethoven-Rezeption in Frankreich: Von ihren Anfängen bis zum Untergang des Second Empire. Bonn: Verlag des Beethoven-Hauses, 1998.

—_. "Europas Beethoven: Ein rezeptionsgeschichtlicher Vergleich". Bonner Beethoven-Studien, 3 (2003), pp. 47-79.

Krummacher, Friedhelm. Geschichte des Streichquartetts (= Das Streichquartett, Handbuch der musikalischen Gattungen 6, 2 vols., editado por Siegfried Mauser). Laaber: Laaber, 2001 y 2003; nueva edición, 3 vols., Laaber: Laaber, 2005.

La Ilustración musical, 1/33 (17-XI-1883), p. 4.

Loos, Helmut. "Gegen den Strom der Zeit. Der Musikwissenschaftler Arnold Schmitz (1893-1980)". Musikgeschichte in Mittel- und Osteuropa. Mitteilungen der internationalen Arbeitsgemeinschaft an der Universität Leipzig, 13 (2012), pp. 232-244.

—_. "Arnold Schmitz as Beethoven Scholar: A Reassessment”. Journal of Musicological Research, 32/23: New Beethoven Research (2013), pp. 150-162.

Loos, Helmut y Klaus-Peter Koch, eds. Beethoven-Rezeption in Mittel- und Osteuropa. Bericht über die Internationale Musikwissenschaftliche Konferenz vom 22. bis 26. Oktober 2014 in Leipzig. Leipzig: Gudrun Schröder, 2015.

Nommick, Yvan. "La intertextualidad: un recurso fundamental en la creación musical del siglo XX". Revista de musicología, 28/1 (2005), pp. 792-806.

Palacios Garoz, Miguel A. Introducción a la música popular castellana y leonesa. Segovia: Junta de Castilla y León y Excmo. Ayuntamiento de Segovia, 1964.

Paulo Selvi, Isabel. "La influencia de Liszt en el panorama musical hispano a raíz de su estancia en la Península Ibérica". Tesis doctoral, Universidad de La Rioja, 2017.

Ringer, Alexander L. "3 Klaviertrios Es-Dur, G-Dur und c-Moll op. 1 (zusammen mit dem Streichquintett c-Moll op. 104)". En Beethoven. Interpretationen seiner Werke, 2 vols., editado por Albrecht Riethmüller, Carl Dahlhaus y Alexander L. Ringer. Laaber: Laaber, 1994, vol. 1, pp. 1-20.

Rolland, Romain. Vie de Beethoven. Vie des Hommes Illustres. París: Librairie Hachette et $C^{\text {ie }}, 1903$; Vida de Beethoven. Vidas de Hombres Ilustres, traducido del francés por Juan Ramón Jiménez. Madrid: Publicaciones de la Residencia de Estudiantes, 1915.

Saldoni, Baltasar. "Día 12, 1814". Diccionario biográfico-bibliográfico de efemérides de músicos españoles, 4 vols. (1868-1881). Madrid: Imprenta a cargo de D. Antonio Pérez Dubrull, 1868, vol. 1, pp. 251-252.

Sánchez, María Almudena. "La Sociedad de Música Clásica di Camera". Cuadernos de Música Iberoamericana, 8-9 (2001), pp. 195-210.

Schmitz, Arnold. Das romantische Beethovenbild. Darstellung und Kritik. Berlin y Bonn: Dümmler, 1927; Darmstadt: Wissenschaftliche Buchgesellschaft, 1978.

Schneider, Herbert. "Streichquartette op. 18". En Beethoven. Interpretationen seiner Werke, 2 vols., editado por Albrecht Riethmüller, Carl Dahlhaus y Alexander L. Ringer. Laaber: Laaber, 1994, vol. 1, pp. 133-150.

Smallman, Basil. The Piano Trio. Its History, Technique, and Repertoire. Oxford: Oxford University Press, 1990; Clarendon paperbacks, 1992.

- The Piano Quartet and Quintet. Style, Structure, and Scoring. Oxford: Oxford University Press, 1994; Clarendon paperbacks, 1996.

Sopeña Ibáñez, Federico. Historia crítica del Conservatorio de Madrid. Madrid: [s. n.], 1967.

Stokes, John. "A Critical Edition of Conrado del Campo's String Quartet No. 8, 'At the Death of his Mother' 
(1913). Defining the Scope of the Critical Process through the Creation of a Musically Viable Score for Interpreters". En The String Quartet in Spain. Varia Musicologica, 22, editado por Christiane Heine y Juan Miguel González Martínez. Berna: Peter Lang, 2016, pp. 583-608.

Stravinsky, Igor. Crónicas de mi vida [1935/36]. El Laberinto, 17, traducción [del francés], edición y notas de Jesús García-Pérez. Barcelona: Nuevo Arte Thor, 1985.

Suárez-Pajares, Javier. “Quintín Esquembre (1885-1965). Vida y obra de un maestro independiente". Roseta. Revista de la Sociedad Española de Guitarra, 2 (V2009), pp. 54-99.

Subirá, José. "Leyendo libros. Vida de Beethoven, por Romain Rollan [sic], traducción de Juan Ramón Jiménez". Vida manchega, 5/164 (10-VII-1916), p. 10.
Tejada Tauste, Torcuato. "El Trío con piano en España en los siglos XIX y XX". Tesis doctoral, Universidad de Granada, 2020.

Tintorer, Pedro. Curso completo de piano. Método teórico-práctico, dividido en dos partes. Barcelona: Faustino Bernareggi, [1878]).

—. Gimnasia diaria del pianista. Colección de ejercicios. Barcelona: Ferrer de Climent e Hijos, [1886]).

Winkelmüller, Marie. Die 'Drei Streichquartette' von Juan Crisóstomo de Arriaga. Ein Beitrag zur Beethoven-Rezeption in Paris um 1825. Freiburger Beiträge zur Musikgeschichte, 13. Freiburg im Breisgau, Berlín y Viena: Rombach, 2009.

Recibido: 02.07.2020

Aceptado: 07.10.2020 